\title{
LAS COMUNIDADES NATIVAS DE LA AMAZONÍA PERUANA Y EL CUMPLIMIENTO DE LOS INCISOS C) Y D) DEL ARTÍCULO 10 DEL CONVENIO SOBRE DIVERSIDAD BIOLÓGICA. SITUACIONES ANÁLOGAS EN LA UNIÓN EUROPEA
}

\author{
RUEDA ROMERO, Paulino Saúl ${ }^{216}$
}

\section{RESUMEN}

En el curso de "Derechos Sociales, Ambientales y Económicos. Perspectiva Internacional, Regional y Nacional" como parte del programa de los XI Cursos Intensivos de Posgrado llevado a cabo en la Facultad de Derecho de la Universidad de Buenos Aires (UBA), hemos desarrollado importantes temas que forman parte del quehacer del mundo globalizado. Uno de los puntos que aún no ha sido tratado eficientemente es el descuido existente sobre la diversidad biológica, en el territorio de las comunidades nativas de la amazonia peruana.

En la conferencia de las naciones unidas sobre el medio ambiente y el desarrollo, se firmó el Convenio sobre la Diversidad Biológica, que obliga a los Estados firmantes a luchar contra la extinción de especies en todo el mundo. Su secretario ejecutivo sostuvo: "los servicios que la naturaleza nos brinda son gratuitos, pero el hombre tiene una inconsciencia profunda de lo que representa su destrucción [...] si la humanidad no pone freno a la degradación de la biodiversidad, el legado para las generaciones futuras quedará hipotecado [...] tengamos el coraje de mirar a nuestros hijos a los ojos y admitir el fracaso [...] admitir que continuamos perdiendo biodiversidad a un ritmo sin precedentes, estaremos hipotecando su futuro". Palabras que rubrican premoniciones futuras acerca del tratamiento de la extinción de una gran parte de la diversidad biológica existente, que si no le damos un tratamiento, su destrucción se aceleraría y estaríamos yendo en contra del nuevo esquema del desarrollo sostenible.

Haciendo un balance de la aplicación de este convenio, nos damos cuenta que la mayoría de los Estados firmantes, promulgaron normas jurídicas a fin de preservar las especies que forman parte de esta biodiversidad; sin embargo, la acción humana, por el hecho de seguir conquistando espacios, sigue depredándolos, sin tener en cuenta el riesgo que significa para las generaciones futuras.

En el presente trabajo, analizo y discuto desde la perspectiva de los derechos sociales, ambientales y económicos, el cumpliendo de los incisos c) y d) del artículo $\mathbf{1 0}^{\circ}$ de dicha convención en las comunidades nativas de la amazonia peruana, zona de permanente conflicto entre el Estado peruano y las comunidades nativas. El trabajo consta de seis partes. La primera explica el marco legal y la jurisprudencia; la segunda abarca la metodología, e implica señalar el método y el planteamiento de las hipótesis; la tercera el marco teórico, el marco geográfico y la recopilación de información; la cuarta el análisis e interpretación; en

${ }^{216}$ El autor es Profesor Investigador del Instituto de Investigación Jurídica de la Facultad de Derecho de la Universidad de San Martín de Porres. Está a su cargo las cátedras de Introducción al Derecho, Filosofía del Derecho y Antropología Jurídica. Telf. 365-7000/4666. C.E.: pruedar@usmp.pe 
la quinta se establece una analogía con algunos resultados de la Unión Europea y países de América del sur; en la sexta parte se formula algunas conclusiones y nuevas perspectivas para el futuro.

\title{
PALABRAS CLAVES
}

Derechos sociales, ambientales y económicos. Comunidades Nativas. Convenio sobre Diversidad Biológica. Desarrollo sostenible. Convenio 169 OIT. Addis Abeba. Unión Europea. Utilización sostenible. Biodiversidad.

\begin{abstract}
In the course of social rights, environmental, and economic. International Perspective, Regional and National" as part of the program of the XI intensive postgraduate carried out at the Faculty of Law at the University of Buenos Aires (UBA), we have developed significant issues that are part of the work of the globalized world. One of the points that has not yet been treated efficiently, it is the carelessness on biological diversity, in the territory of the native communities of the Peruvian Amazon.
\end{abstract}

In the United Nations conference on environment and development, signed the Convention on Biological Diversity, which obliges the signatory States to combat the extinction of species throughout the world. Its executive secretary said: "the services that nature offers us are free, but the man has a deep unconscious of what he represents their destruction [...] If humanity does not brake to the degradation of biodiversity, the legacy for future generations will be mortgaged [...] must have the courage to look our children in the eye and admit failure [...] admit that we continue losing biodiversity at an unprecedented pace, we are mortgaging their future". Words that initialled by premonitions future about the treatment of the extinction of a large part of the existing biodiversity, that if we do not a treatment, their destruction would speed up and we would be going against the new scheme of sustainable development.

Doing a balance of the application of this convention, we realize that the majority of the signatory States, enacted legal rules in order to preserve the species which are part of this biodiversity; However, human action, by the fact to continue conquering spaces, continues depredándolos without taking into account the risk that means for future generations. In this paper, I analyze and discuss from the perspective of social rights, environmental, and economic, compliance with subparagraphs (c) and (d) of article $10^{\circ}$ of the said convention in the native communities of the Peruvian Amazon, an area of permanent armed conflict between the Peruvian State and the native communities.

The work consists of six parts. The first explains the legal framework and jurisprudence; the second covers the methodology, and will draw attention to the method and the approach of hypotheses; the third the theoretical framework, the geographical framework and the gathering of information; The fourth on analysis and interpretation; in the fifth set out an analogy with some of the results of the European Union and countries of south America; in the sixth part formulates some conclusions and new perspectives for the future. 


\section{KEYWORDS}

Social rights, environmental, and economic. Native Communities. Convention on Biological Diversity. Sustainable Development. Convention 169 OIT. Addis Ababa. European Union. Sustainable Use.Biodiversity.

\section{SUMARIO}

Marco legal. Del convenio. Concordancia. Marco metodológico. Elección del tema y objeto de estudio. Hipótesis. El marco conceptual y el geográfico. Marco conceptual. Definición operacional. Marco geográfico. La geografía amazónica. Familias etnolingüísticas y grupos étnicos en la Amazonía peruana. Análisis e interpretación. Artículo 10: utilización sostenible de los componentes de la diversidad biológica inciso c). Artículo 10. utilización sostenible de los componentes de la diversidad biológica. inciso d). Comprobación del cumplimiento en función de la hipótesis. Concordancia: programa 21 desarrollo sostenible. Reconocimiento y fortalecimiento del papel de las poblaciones indígenas y sus comunidades. El convenio 169 OIT. Directrices de Addis Abeba. Analogías. La unión europea: utilización sostenible de la biodiversidad, artículo 10 del convenio incisos a), b), c) y d).A manera de conclusión. Bibliografía.

Las Comunidades Nativas de la Amazonía Peruana y el Cumplimiento de los incisos c) y d) del artículo 10 del Convenio sobre Diversidad Biológica. Situaciones análogas en la Unión Europea ${ }^{217}$.

\section{INTRODUCCIÓN.}

En julio del 2010 participé en el curso de los "Derechos sociales, ambientales y económicos: perspectiva internacional, regional y nacional" en la Facultad de Derecho de la Universidad de Buenos Aires. Uno de los temas tratados fue acerca del Convenio de la Diversidad Biológica sobre todo el artículo 10, sus incisos "c" y "d" que a la letra dice: "Artículo 10. Utilización sostenible de los componentes de la diversidad biológica. Cada Parte Contratante, en la medida de lo posible y según proceda:

c) Protegerá y alentará, la utilización consuetudinaria de los recursos biológicos, de conformidad con las prácticas culturales tradicionales que sean compatibles con las exigencias de la conservación o de la utilización sostenible;

d) Prestará ayuda a las poblaciones locales para preparar y aplicar medidas correctivas en las zonas degradadas donde la diversidad biológica se ha reducido”.

Como resultado de estas discusiones, es la presente investigación que lo aplico a las comunidades de la amazonia peruana, donde el Estado peruano está interesado en mantener las zonas protegidas de la selva con la finalidad de evitar la explotación de la diversidad biológica allí existente.

\footnotetext{
${ }^{217} \mathrm{El}$ acta que yo entregué a mediados de diciembre/2010. Su nota final (que por cierto es Sobresaliente, muy buen trabajo). Mag. SILVIA CORIA (Directora del curso "Derechos Sociales, Ambientales y Económicas. Perspectiva Internacional, Regional y Nacional")
} 
Escogí esta zona porque el convenio subraya el papel de las comunidades locales y poblaciones indígenas en materia de conservación de la biodiversidad. En efecto, estas poblaciones dependen estrecha y tradicionalmente de los recursos biológicos en los que se basan sus tradiciones; son las más vulnerable del país, donde la población nativa mantiene aún sus costumbres ancestrales, su cosmovisión propia y su relación con la tierra y la naturaleza forma parte de su vida cotidiana; a pesar de ello, muchas comunidades están orientando su producción hacia el mercado, pasando de una economía de autosuficiencia con una producción familiar a una mixta, en la que se produce para el consumo doméstico pero también para el mercado.

La conservación y la explotación sostenible de la diversidad biológica son indispensables para alcanzar un desarrollo sostenible, así como los objetivos del milenio para el desarrollo relativo a la pobreza, la salud y el medio ambiente. En la cumbre mundial sobre el desarrollo sostenible de Johannesburgo, fue reconocido como el instrumento principal en esta materia, donde los Jefes de Estado allí reunidos, se pusieron de acuerdo sobre la necesidad de reducir el índice de pérdida de la diversidad biológica de forma significativa y el Consejo Europeo de Gotemburgo adoptó el objetivo de detener la pérdida de diversidad biológica para el 2010, responsabilizando a los Estados su conservación y la utilización sostenible.

La información y los conocimientos sobre la diversidad biológica son todavía insuficientes; para mantenerla, resulta necesario desarrollar capacidades científicas, técnicas e institucionales con el objeto de lograr un entendimiento básico que permita planificar y aplicar las medidas adecuadas. Su conservación, la utilización sostenible de sus componentes y el reparto justo y equitativo de los beneficios derivados del uso de los recursos genéticos a través del acceso adecuado.

De conformidad con la Carta de las Naciones Unidas, los Estados tienen el derecho soberano de explotar sus propios recursos en aplicación de su propia política ambiental y la obligación de asegurar que las actividades que se lleven a cabo dentro de su jurisdicción o bajo su control no perjudiquen al medio de otros Estados o de zonas situadas fuera de toda jurisdicción nacional; el convenio recomienda el fomento de la conciencia pública y la propagación a través de medios de información así como la inclusión de estos temas en los programas educativos sobre la importancia de la conservación de la diversidad biológica.

Finalmente hago una analogía con la forma en que la Unión Europea está dando el tratamiento al artículo pertinente y ésta cubre un área geográfica muy vasta y diversa, que alberga numerosos tipos de ecosistemas y especies. Sin embargo, la diversidad biológica se encuentra amenazada a todo lo largo y ancho de la UE. Según la Agencia Europea de Medio Ambiente (AEMA) y otras organizaciones, el tamaño de los hábitats sigue disminuyendo y están cada vez más fragmentados en forma similar con lo que ocurre en las comunidades nativas de la Amazonía peruana. Estos paradigmas hay que tenerlos presente a fin de fomentar políticas de desarrollo y conservación de la biodiversidad en la tierra. 


\section{I.- MARCO LEGAL.}

\section{1.- DEL CONVENIO:}

"Artículo 10. Utilización sostenible de los componentes de la diversidad biológica.

Cada Parte Contratante, en la medida de lo posible y según proceda:

Inciso c) Protegerá y alentará la utilización consuetudinaria de los recursos biológicos, de conformidad con las prácticas culturales tradicionales que sean compatibles con las exigencias de la conservación o de la utilización sostenible;

Inciso d) Prestará ayuda a las poblaciones locales para preparar y aplicar medidas correctivas en las zonas degradadas donde la diversidad biológica se ha reducido";

\section{2.- CONCORDANCIA: \\ PROGRAMA 21 DESARROLLO SOSTENIBLE:}

- "Reconocimiento y fortalecimiento del papel de las poblaciones Indígenas y sus comunidades".

\section{II.- MARCO METODOLÓGICO.}

\section{1.- Elección del tema y objeto de estudio.}

En uno de los documentos entregados a los participantes en el Curso "Derechos Sociales, Ambientales y Económicos. Perspectiva Internacional, Regional y Nacional", titulado "Carta a la tierra" ${ }^{218}$, el segundo principio, me llamó poderosamente la atención que a la letra dice:

"5. Proteger y restaurar la integridad de los sistemas ecológicos de la Tierra, con especial preocupación por la diversidad biológica y los procesos naturales que sustentan la vida.

a. Adoptar, a todo nivel, planes de desarrollo sostenible y regulaciones que permitan incluir la conservación y la rehabilitación ambientales, como parte integral de todas las iniciativas de desarrollo.

b. Establecer y salvaguardar reservas viables para la naturaleza y la biosfera, incluyendo tierras silvestres y áreas marinas, de modo que tiendan a proteger los sistemas de soporte a la vida de la Tierra, para mantener la biodiversidad y preservar nuestra herencia natural.

c. Promover la recuperación de especies y ecosistemas en peligro.

d. Controlar y erradicar los organismos exógenos o genéticamente modificados, que sean dañinos para las especies autóctonas y el medio ambiente; y además, prevenir la introducción de tales organismos dañinos.

\footnotetext{
${ }^{218}$ Entre las muchas recomendaciones incluidas en Nuestro Futuro Común (1987) —informe de la Comisión Mundial sobre Medio Ambiente y Desarrollo (CMMAD) - se encontraba la iniciativa para crear una "Declaración Universal sobre la Protección Ambiental y el Desarrollo Sostenible" en la forma de una "nueva Carta" cuyos principios guiaran a las naciones en la transición hacia el desarrollo sostenible. Basándose en esta recomendación, Maurice F. Strong, Secretario General de la Cumbre de la Tierra (Conferencia de las Naciones Unidas sobre el Medio Ambiente y el Desarrollo, celebrada en Río de Janeiro en 1992), propuso que se redactara y se adoptara la Carta de la Tierra mientras se desarrollaba dicha Cumbre. Durante el proceso preparatorio de la misma se celebraron consultas intergubernamentales sobre la Carta de la Tierra, pero no se logró un acuerdo intergubernamental con respecto a sus principios. La "Declaración de Río" que promulgara la Cumbre contuvo una valiosa serie de principios pero no satisfizo el aspecto de la visión ética inclusiva que mucha gente había esperado encontrar en la Carta de la Tierra.
} 
e. Manejar el uso de recursos renovables como el agua, la tierra, los productos forestales y la vida marina, de manera que no se excedan las posibilidades de regeneración y se proteja la salud de los ecosistemas.

f. Manejar la extracción y el uso de los recursos no renovables, tales como minerales y combustibles fósiles, de forma que se minimice su agotamiento y no se causen serios daños ambientales".

El inciso a) no solo recomienda, sino que ordena elaborar planes de desarrollo sostenible a fin de llevar a cabo las regulaciones que permitan incluir la conservación y la rehabilitación ambientales como parte integrante de todas las iniciativas de desarrollo. Desde esta perspectiva, se deja de lado, toda forma de conceptualizar el desarrollo, como las definiciones iniciales que establecían las diferencias entre países desarrollados y subdesarrollados medidos según el grado de crecimiento únicamente, Las definiciones de Rostow $^{219}$ por ejemplo ya pasaron a la historia.

Por otro lado, el inciso b) señala con mucha claridad salvaguardar las reservas viables para la naturaleza y biosfera [...] para mantener la biodiversidad. Lo que ordena este inciso es que debemos tener mucho tacto en hacer un uso exclusivo, sino, inclusivo de las reservas, teniendo en cuenta los que habitan en estas áreas que se vienen depredando continuamente.

${ }^{219}$ Rostow, Walter whitman (1980)Las Etapas del crecimiento económico. México, F.C.E. Desarrolla un modelo de crecimiento estructurado en etapas, desde el estado original de subdesarrollo que considera a la sociedad tradicional, a la etapa de consumo en masa. Este modelo de crecimiento económico es una de las claves de la llamada Teoría del desarrollo. Primera etapa sociedad tradicional. La economía de este período se caracteriza por una actividad de subsistencia, donde la totalidad de la producción está destinada al consumo de los productores, más que para el comercio. Este comercio a pequeña escala se desarrolla gracias a sistemas de intercambio de mercancías y bienes, a modo de trueques, en una sociedad donde la agricultura es la industria más importante. La mano de obra empleada contrasta con la escasa cantidad de capital invertido, a la vez que la localización de los productos está firmemente determinada por los métodos tradicionales de producción. Segunda etapa de transición (condiciones previas para el "despegue económico") El incremento de la especialización en el trabajo genera excedentes para el comercio, a la vez que emerge una incipiente infraestructura de transportes para propiciar las relaciones comerciales. Por otra parte, los ingresos hacen que el ahorro y la inversión crezcan, facilitando la aparición de nuevos empresarios. Asimismo, se dan relaciones comerciales con el exterior que se concentran fundamentalmente en productos primarios básicos. Tercera etapa el despegue económico. Auméntala industrialización, con un número cada vez mayor de trabajadores que se desplazan de la agricultura a la industria. No obstante, este crecimiento se concentra en ciertas regiones del citado país y en una o dos industrias manufactureras; mientras, el nivel de inversión alcanza el 10\% del PIB. Las transiciones económicas están acompañadas por la evolución de nuevas instituciones políticas y sociales que respaldaban la industrialización. El crecimiento es auto-sostenible a la vez que las inversiones conducen a un incremento de los ingresos que genera una mayor cantidad de ahorro para inversiones futuras. cuarta etapa camino de la madurez La economía se diversifica en nuevas áreas, gracias a que la innovación tecnológica proporciona un abanico diverso de oportunidades de inversión. Además, la economía produce una gran diversidad de bienes y servicios de los que hay menos dependencia respecto de las importaciones. Quinta etapa consumo a gran escala La economía está avanzando hacia el consumo masivo, lo que hace que florezcan industrias duraderas de bienes de consumo. El sector servicios se convierte crecientemente en el área dominante de la economía. De acuerdo con Rostow, el desarrollo requiere una inversión sustancial de capital. Para las economías de los LDC (LowDevelopedCountries), las condiciones necesarias para este crecimiento deberían haber sido creadas en esta etapa, al igual que si se les suministra ayuda o se realiza cualquier inversión extranjera en la tercera etapa, la economía local debería haber alcanzado la segunda etapa, lo que, de haber sido así, debería llevar a un rápido crecimiento. Por el contrario, se critica a Rostow que su modelo fue desarrollado considerando únicamente a las culturas occidentales, sin poder ser aplicable a los LDC's. Asimismo, no detalla las condiciones previas para el crecimiento, a la vez que estas etapas son difícilmente identificables en la realidad según van emergiendo juntas. Así pues, resalta como elemento principal para el crecimiento económico la inversión, no tanto como el desarrollo en un significado amplio. 
Estos aspectos me han iluminado para escoger el presente tema, que espero desarrollarlos en cumplimiento de los incisos c) y d) del artículo 10 de la Convención sobre Diversidad Biológica (CDB).

\section{2.-Objeto del estudio}

a. Explicar las formas de conservación de la diversidad biológica en las Comunidades Nativas de la Amazonía peruana mediante los sistemas ancestrales.

b. Señalar las amenazas de la explotación y sobreexplotación de diferentes especies que forma esta diversidad.

c. Establecer analogías con otras realidades entre ellas, la Unión Europea y algunos países latinoamericanos.

\section{3.- Hipótesis}

2.3.1.- Las comunidades nativas de la Amazonía peruana conservan desde tiempos ancestrales su diversidad biológica, haciendo uso adecuado de la flora y fauna para el sustento familiar.

2.3.2.- El concepto de diversidad biológica se sustenta en la conservación de plantas que lo consideran sagradas para el uso de medicina tradicional

2.3.3.- Su territorio es sagrado y forma parte de la vida de la población nativa.

2.3.4.-El Estado no implementa el convenio 169 de la OIT que trae consigo el desarrollo de conflictos sociales.

\section{III.- EL MARCO CONCEPTUAL Y EL GEOGRÁFICO. 3.1.-MARCO CONCEPTUAL 3.1.1.- Del Convenio}

\section{Antecedentes}

Veamos en primer lugar a manera de diagnóstico, los principales acontecimientos, propuestas, pronunciamientos y fundamentos que dieron origen al convenio. Así, el Programa de las Naciones Unidas para el Medio Ambiente (PNUMA) ${ }^{220}$, en 1987 reconoció la necesidad de incrementar y canalizar los esfuerzos internacionales para proteger la diversidad biológica, creando para ello, un grupo de trabajo para investigar "la conveniencia de elaborar un convenio de carácter general y la forma que podría adoptar con el fin de racionalizar las actividades en curso en esta esfera y abordar otras esferas que correspondan al ámbito de aplicación de dicho convenio" (PNUMA, Decisión del Consejo de Administración 14/26, 1987). La primera reunión del grupo a finales de 1988, concluyó que los convenios existentes trataban cuestiones específicas sobre la conservación de la diversidad biológica, pero que en razón de su marcada especificidad, no respondían adecuadamente a las necesidades de conservación de la diversidad biológica a nivel global.

\footnotetext{
${ }^{220}$ Programa de Naciones Unidas para el Medio Ambiente, PNUMA.Fue creado por recomendación de la Conferencia de las Naciones Unidas sobre el Desarrollo Humanos (Estocolmo - 1972). tiene como misión dirigir y alentar la participación en el cuidado del medio ambiente inspirando, informando y dando a las naciones y a los pueblos los medios para mejorar la calidad de vida sin poner en riesgo las de las futuras generaciones.
} 
Así mismo, en 1990 el grupo de trabajo concluyó que se necesitaba un tratado global sobre conservación de la diversidad biológica. La Unión Internacional para la conservación de la naturaleza, realizó un fundamental aporte a través de propuestas elaboradas por la Comisión de Derecho Ambiental, estas propuestas, junto con las de la FAO y el PNUMA, fueron la base para un primer borrador del Convenio. El proceso formal de negociaciones se inició en febrero de 1991, cuando el grupo de trabajo cambió su denominación a Comité Intergubernamental de Negociación de un Convenio sobre la Diversidad Biológica. La fecha impuesta para la firma del Convenio, la cual debería suceder durante la Convención de las Naciones Unidas del Medio Ambiente y Desarrollo (CNUMAD), que sirvió como incentivo para el acuerdo final sobre el contenido del Convenio.

Siguiendo con la secuencia, en 1992 se celebró la Conferencia de las Naciones Unidas sobre Medio Ambiente y Desarrollo, aquí se firmaron dos acuerdos jurídicamente vinculantes de gran importancia ambiental: la Convención Marco de las Naciones Unidas sobre el Cambio Climático y el Convenio sobre la Diversidad Biológica (CDB), que ganó rápidamente una aceptación general, donde más de ciento cincuenta gobiernos, firmaron el documento en el marco de la Cumbre en Río de Janeiro.

Uno de los mayores logros, es su enfoque holístico, integral, al definirla en sus tres dimensiones: genes, ecosistemas y especies. Es "la variabilidad de organismos vivos de cualquier fuente, incluidos entre otras cosas, los ecosistemas terrestres, marinos y otros ecosistemas acuáticos, así como los complejos ecológicos de los que forman parte y, comprende la diversidad dentro de cada especie y de los ecosistemas ${ }^{221}$ ". Se señalan metas de gran alcance y aborda la cuestión fundamental del futuro de la humanidad, constituyéndose en un hito en el derecho internacional.Reconoce por primera vez, que la conservación de la diversidad biológica, es una preocupación común para la humanidad y forma parte del proceso de desarrollo, el convenio abarca todos los ecosistemas, especies y recursos genéticos respetando la soberanía de las Partes.

Establece nexos entre las medidas tradicionales de conservación y la meta económica de utilizar en forma sostenible los recursos biológicos, sienta principios para la distribución justa y equitativa de los beneficios resultantes del uso de recursos genéticos, abarca la rápida expansión en el ámbito de la biotecnología, aborda temas de desarrollo y transferencia de tecnologías, la distribución de beneficios y la seguridad de las biotecnologías. Recuerda a los encargados de la toma de decisiones, que los recursos naturales no son infinitos y establece una nueva filosofía para el siglo XXI, es el uso sostenible.Reconoce que los ecosistemas, las especies y los genes deben utilizarse en beneficio de la humanidad, sin afectar la diversidad biológica.

Continuando con el diagnóstico, en el 2002, estos mismos países pactaron frenar la frenética pérdida de especies que sufre el planeta. La fecha fijada era este año, 2010. Sin embargo, la extinción de la fauna y flora mundial sigue siendo un problema que no se ha resuelto y eso es, precisamente, lo que pretende solucionar esta cumbre. Según el último informe de la Unión Internacional para la Conservación de la Naturaleza, que se hizo público en 2009, más de mil cien especies de animales estarían ya extintas y casi diez y siete mil están en peligro de desaparecer.

${ }^{221}$ Artículo 2 del CDB "términos utilizados" 
Los medios de comunicación nos informan que a este ritmo, la tierra se enfrentaría a la sexta gran extinción de la historia en lo que a biodiversidad biológica se refiere, si se tiene en cuenta las pérdidas de fauna y flora. También la ONU presentó una serie de datos nada halagüeños a la hora de implicar a los delegados de los diferentes países, a llegar a un plan estratégico real y posible, para evitar la pérdida de la biodiversidad biológica; así, una de cada ocho especies de aves está a punto de desaparecer, uno de cada tres anfibios se encuentra en peligro de extinción y lo mismo pasa, aunque en diferentes proporciones con los mamíferos.

La revista Science ${ }^{222}$, analizó la situación de 25.780 especies de la "lista roja" de la Unión Internacional para la Conservación de la Naturaleza (UICN) de especies amenazadas, para investigar la situación de los vertebrados del mundo (mamíferos, aves, anfibios, reptiles y peces). Los resultados muestran que, en promedio, cincuenta y dos especies de mamíferos, aves y anfibios se acercan cada año a la extinción debido a los impactos de la expansión agrícola, como la tala, sobreexplotación y las invasiones de especies exóticas.

Estos son sólo algunos ejemplos de una problemática mundial que debe controlarse urgentemente. Entre las causas que provocan este desastre ecológico, se encuentra la sobreexplotación de recursos, la contaminación, la modificación de los hábitats y el cambio climático. Este último, la humanidad lo viene soportando con mayor fuerza, así nos informan los medios de comunicación social, la desglaciación y la pérdida de ingentes recursos forestales y de fauna silvestre son evidentes a medida que pasan los años.

\subsection{2.-Del preámbulo del convenio}

El preámbulo señala entre otros: "Los países miembros conscientes del valor intrínseco de la diversidad biológica y de los valores ecológicos, genéticos, sociales, económicos, científicos, educativos, culturales, recreativos y estéticos de la diversidad biológica y sus componentes [...] de la importancia de la diversidad biológica para la evolución y para el mantenimiento de los sistemas necesarios para la vida de la biósfera, afirman que la conservación de la diversidad biológica, es interés común de toda la humanidad, que los Estados tienen derechos soberanos sobre sus propios recursos biológicos, por tanto, son responsables de la conservación de su diversidad biológica y de la utilización sostenible de sus recursos biológicos".

"Preocupados por la considerable reducción de la diversidad biológica como consecuencia de determinadas actividades humanas [...] conscientes de la general falta de información y conocimientos sobre la diversidad biológica y de la urgente necesidad de desarrollar capacidades científicas, técnicas e institucionales para lograr un entendimiento básico que permita planificar y aplicar las medidas adecuadas [...] observando que es vital prever, prevenir y atacar en su fuente las causas de reducción o pérdida de la diversidad biológica; que cuando exista una amenaza de reducción o pérdida sustancial de la diversidad biológica no debe alegarse la falta de pruebas científicas inequívocas como razón para aplazar las medidas encaminadas a evitar o reducir al mínimo esa amenaza".

\footnotetext{
${ }^{222}$ Revista especializada de mayor circulación. Es una revista científica y órgano de expresión de la AAAS (American AssociationfortheAdvancement of Science: Asociación Estadounidense para el Avance de la Ciencia).
} 
Es muy clara la preocupación mostrada por los presidentes y jefes de Estado al hacer un balance y diagnóstico de la diversidad biológica, si se continúa con la constante depredación de los mismos, las generaciones futuras estarán desamparadas; de allí que señalan con meridiana claridad los objetivos que han de perseguir como: la conservación de la diversidad biológica, la utilización sostenible de sus componentes y la participación justa y equitativa en los beneficios que se deriven de la utilización de los recursos genéticos, mediante, entre otras cosas, del acceso adecuado a esos recursos y una transferencia apropiada de las tecnologías pertinentes. Teniendo en cuenta todos los derechos sobre los recursos y las tecnologías, así como mediante una financiación apropiada, se pueden cumplir los objetivos señalados.

No dudamos del derecho soberano que tienen los Estados sobre sus recursos, sin embargo, estos mismos lo vienen depredando en función de una mayor captación de ingresos con la finalidad de cumplir con sus gastos públicos. Muchos no han tomado las medidas necesarias a fin de evitar la depredación de dichos recursos, como la minería por ejemplo, que ha cambiado el hábitat, no solo de los seres humanos, sino también de muchas especies. En el caso de las comunidades nativas de la amazonia peruana, la explotación del petróleo, amenaza permanentemente la extinción de muchas especies naturales, contaminan las aguas de los ríos y empobrecen a los miembros de las comunidades nativas.

Este derecho soberano del Estado, debe ser compartido con las poblaciones existentes en estas áreas. Revisando la historia, fue el Estado el que a través de los gobiernos, fueron los agentes que incentivaron dicha depredación. Nunca es tarde. Los gobiernos ahora, tienen la responsabilidad de hacer cumplir este convenio.

\subsection{3.- Definición operacional}

En el marco conceptual y siguiendo los lineamientos de la Convención de la Diversidad Biológica firmada por los Estados miembros y, con la finalidad de aclarar los conceptos, se hace la siguiente definición operacional tomada del mismo texto:

Área protegida. Es el área definida geográficamente que ha sido designada o regulada y administrada a fin de alcanzar objetivos específicos de conservación.

Condiciones in situ. En que existen recursos genéticos dentro de ecosistemas y hábitats naturales y, en el caso de las especies domesticadas o cultivadas, en los entornos en que hayan desarrollado sus propiedades específicas.

Conservación ex situ.Se entiende la conservación de componentes de la diversidad biológica fuera de sus hábitats naturales.

Conservación in situ.Se entiende la conservación de los ecosistemas y los hábitats naturales y el mantenimiento y recuperación de poblaciones viables de especies en sus entornos naturales y, en el caso de las especies domesticadas y cultivadas, en los entornos en que hayan desarrollado sus propiedades específicas.

Diversidad biológica. Es la variabilidad de organismos vivos de cualquier fuente, incluidos, entre otras cosas, los ecosistemas terrestres y marinos y otros ecosistemas acuáticos y los complejos ecológicos de los que forman parte; comprende la diversidad dentro de cada especie, entre las especies y de los ecosistemas. 
Ecosistema. Es un complejo dinámico de comunidades vegetales, animales y de microorganismos y su medio no viviente que interactúan como una unidad funcional.

Especie domesticada o cultivada. Especie en cuyo proceso de evolución han influido los seres humanos para satisfacer sus propias necesidades.

Hábitat. Es el lugar o tipo de ambiente en el que existen naturalmente un organismo o una población.

Material genético. Es todo material de origen vegetal, animal, microbiano o de otro tipo que contenga unidades funcionales de la herencia.

Organización de integración económica regional. Es una organización constituida por Estados soberanos de una región determinada, a la que sus Estados miembros han transferido competencias en los asuntos regidos por el presente Convenio y que ha sido debidamente facultada, de conformidad con sus procedimientos internos, para firmar, ratificar, aceptar o aprobar el Convenio o adherirse a él.

País de origen de recursos genéticos. Es el país que posee esos recursos genéticos en condiciones in situ.

País que aporta recursos genéticos. Es el país que suministra recursos genéticos obtenidos de fuentes in situ, incluidas las poblaciones de especies silvestres y domesticadas, o de fuentes ex situ, que pueden tener o no su origen en ese país.

Recursos biológicos. Son los recursos genéticos, los organismos o partes de ellos, las poblaciones, o cualquier otro tipo del componente biótico de los ecosistemas de valor o utilidad real o potencial para la humanidad.

Recursos genéticos. Es el material genético de valor real o potencial.

Utilización sostenible. Es la utilización de componentes de la diversidad biológica de un modo y a un ritmo que no ocasione la disminución a largo plazo de la diversidad biológica, con lo cual se mantienen las posibilidades de ésta de satisfacer las necesidades y las aspiraciones de las generaciones actuales y futuras

\subsection{3.- Utilización y depredación de los recursos genéticos de las poblaciones amazónicas}

El convenio reconoce la estrecha y tradicional dependencia de muchas comunidades locales y poblaciones indígenas que tienen sistemas de vida tradicionales basados en los recursos biológicos, y la conveniencia de compartir equitativamente los beneficios que se derivan de la utilización de los conocimientos tradicionales, las innovaciones y las prácticas pertinentes para la conservación de la diversidad biológica y la utilización sostenible de sus componentes.

Desde este punto de vista, el marco conceptual está planteado, sin embargo, es necesario explicitar temas que aún no han sido lo suficientemente desarrollados, como la presión de los mercados en la permanente depredación de la biodiversidad biológica. La aplicación de una economía de libre mercado en condiciones de bajos precios internacionales para los productos tradicionales de origen tropical, acompañado de tendencias crecientes para 
los precios de fertilizantes, conducirá inicialmente a un empobrecimiento de los agricultores más pobres explotando tierras marginales. Esto, a su vez, incrementará la presión por deforestación y degradación de la Amazonía.

Este fenómeno podrá extenderse en el tiempo, a menos que la economía, en las áreas más fértiles de la Amazonía y el resto del país, reaccione rápidamente ante las oportunidades y nuevas reglas de juego del modelo económico, generando empleo y oportunidades productivas para los más pobres. Esta reacción será difícil o imposible en el sector agrario si no ocurre una efectiva modernización productiva para reducir costos de producción e incrementar la calidad y si no se abren mercados para nuevos productos de la Amazonía.

Es en el sector de la Amazonía peruana donde se han dado las formas más deplorables de sobreexplotación de la madera, produciéndose la deforestación y explotación de la población nativa, adjunta a ella están las apropiaciones del conocimiento y saberes nativos por laboratorios y empresas transnacionales, que hicieron del conocimiento nacional verdaderos negocios, al patentar no solo la riqueza biológica, sino también sus saberes tradicionales. Debe darse un giro completo a este problema, debería existir una interrelación, un toma y daca, estas empresas farmacéuticas transnacionales deberían ser partícipes de los esfuerzos de preservación y uso de la biodiversidad e invertir en la domesticación de las plantas cuyos productos son hoy de manejo extractivo.

La domesticación es la única forma de convertir estos productos en cultivos estandarizados, maximizando la concentración del producto activo y hacer más confiable y eficiente su producción. Este compromiso implica renunciar parcialmente al lucro potencial de la industria químico-farmacéutica en el corto plazo, para promover la justa distribución de los ingresos entre recolectores y agricultores amazónicos y, por ende, proteger los recursos naturales amazónicos, disminuyendo presiones de pobreza sobre el bosque.

El caso de las plantas medicinales como la "sangre de grado" (cicatrizante), "uña de gato" (desinflamante), "ojé" (antihelmíntico), "chanca piedra" (solvente de cálculos renales y hepáticos) y otras, se requerirá un compromiso de las empresas farmacéuticas transnacionales, de sintetizar los productos activos del efecto curativo de cada una de ellas, sólo en casos excepcionales y pagando los "royalties" a las sociedades locales dueñas del conocimiento. Esta simbiosis daría lugar al reconocimiento de la riqueza amazónica cuya única propietaria son las comunidades nativas dela selva y se evitaría en esta forma, la depreciación no solo de los suelos, sino también de toda la biodiversidad existente.

Hoy, dichas empresas farmacéuticas gozan de franquicias al patentar y hacerlas suyas la explotación de estas riquezas generando conflictos sociales que se agudiza por la inacción del Estado, agregándose a ello las continuas colonizaciones que se vienen sucediendo, esto, muchas veces propiciadas por algunos organismo no gubernamentales, o por los propios interesados en depredar las riquezas existentes. A menudo se observan "invasiones" de grupos a fin de asentarse en los territorios que pertenecen a las comunidades nativas, estos asentamientos, debido a la extensión del territorio de la selva, van formalizándose. Otras veces, se dedican a cultivos ilegales de plantas con fines lucrativos, llegan a depredar parte de estos territorios. De allí surge la necesidad de proteger la biodiversidad. 


\section{2.- MARCO GEOGRÁFICO}

\subsection{1.- La geografía amazónica}

Empecemos por ubicar a las comunidades nativas en el mapa del Perú:

Las Regiones donde están asentadas las Comunidades Nativas son: Loreto, Ucayali, San Martín, Cusco, Madre de Dios, Puno, Junín, Pasco y Ayacucho. La Amazonía peruana tiene diferentes clasificaciones de ecosistemas de acuerdo a criterios usados por diferentes autores. Según el ecólogo peruano Antonio $\mathrm{Brack}^{223}$ la Selva Alta se ubica entre los quinientos y mil novecientos msnm al lado oriental tropical y subtropical de la cordillera de los Andes. Tiene un relieve bastante ondulado y con una hidrografía de ríos torrentosos. El clima es cálido y húmedo, con fuertes precipitaciones de noviembre a abril, y una temporada de menos lluvia, de mayo a octubre. La gradiente altitudinal proporciona diversos climas y zonas que forman ecosistemas diferenciados a menor escala y una gran diversidad biológica.

La Selva Baja a gran escala es un ecosistema ubicado entre los noventa y quinientos msnm, presenta un relieve bastante plano con algunas elevaciones, es denominado "llanura amazónica" y ocupa la mayor parte del territorio amazónico peruano. Se caracteriza por clima tropical de altas temperaturas y fuertes precipitaciones, fisiografía mayormente llana y abundante vegetación y biodiversidad. A una escala menor, se presenta una gran diversidad o mosaico de ecosistemas originados por procesos geológicos y climáticos.

La Sabana de Palmeras es un ecosistema hidromórfico, con vegetación herbácea, con dominancia de monocotiledóneas, y asociaciones de arbustos, palmeras y árboles dispersos en la periferia. Las especies están adaptadas al drenaje casi total, durante la estación seca mayor de cinco meses, y a las inundaciones por acumulación del agua de lluvias y por efecto de filtración del sistema de vasos comunicantes de los ríos Heath y Palma Real, durante los períodos de creciente. En el interior se hallan parches o bosquetes de palmales, como pequeños "aguajales ${ }^{224}$ puros y mixtos".

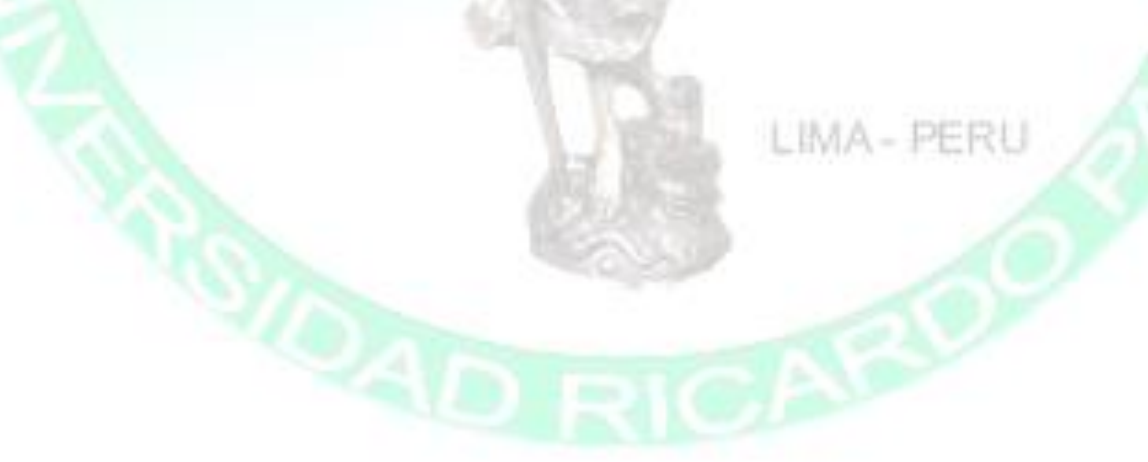

${ }^{223}$ Hoy Ministro del Ambiente utiliza la división de la selva en: Selva Alta y Selva Baja a la que agrega la Sábana de palmeras.

${ }^{224}$ Denominación local que reciben las formaciones vegetales de zonas inundables en la cuenca amazónica 


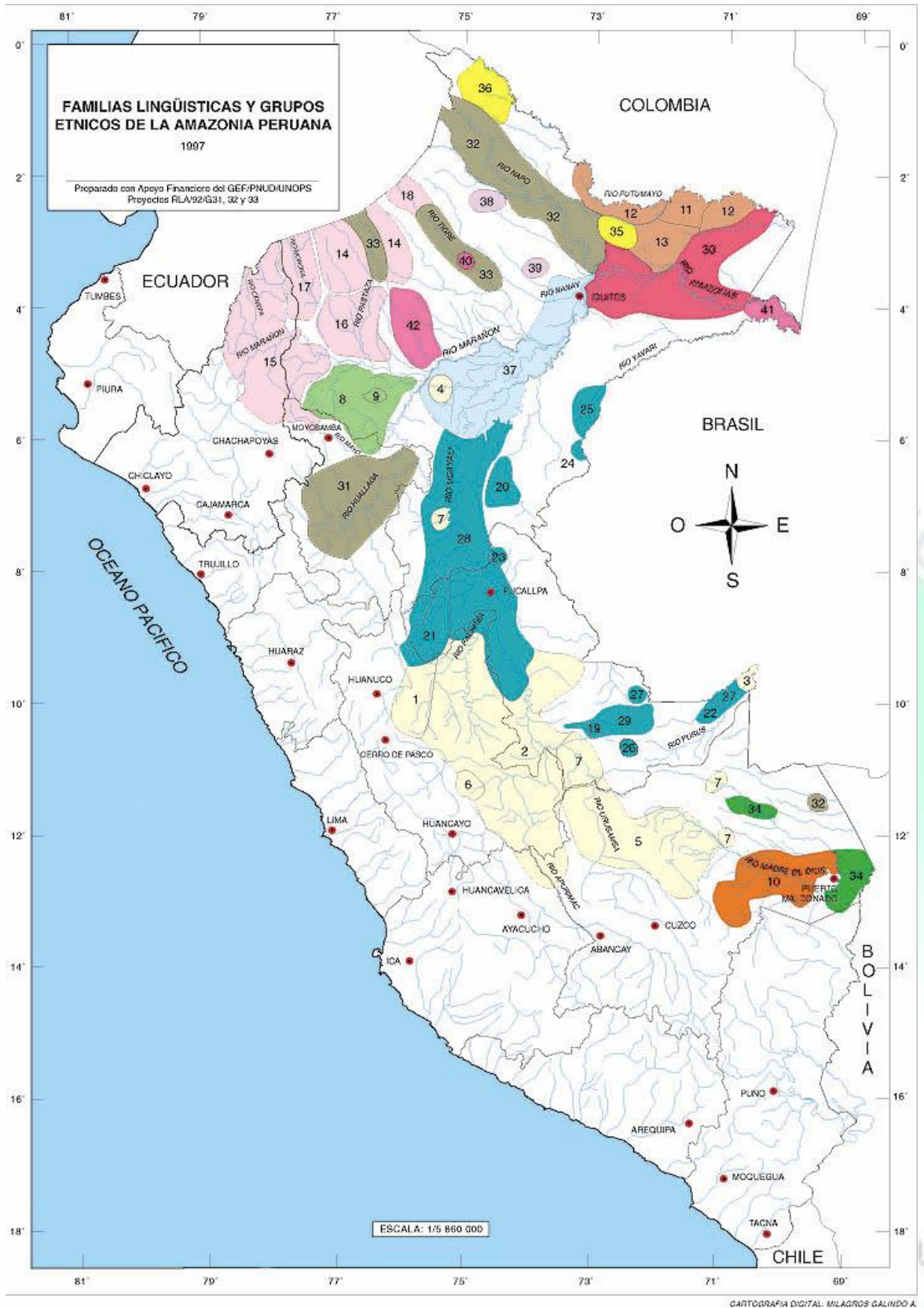

\subsection{2.- La vida en las comunidades nativas, su cultura y ecología}

El mundo para los pueblos de la amazonia está centrado en la tierra y el bosque desde una visión holística, su visión del mundo que los rodea está centrado en la realidad que viven, los ríos, las lagunas, los animales, las plantas, las montañas, las cataratas, se materializan y cobran una vida autónoma a través de las costumbres, mitos, leyendas y muchas veces estos elementos son convertidos en dioses y espíritus. La naturaleza convive en estrecha relación armoniosa con el mundo de las personas donde se construyen relaciones de equilibrio que muchas veces conlleva a la mantención y sostenibilidad de los recursos ecológicos; su espacio no tiene límites y no es propiedad de nadie, ya que estos elementos son propios y autónomos. 
El hombre en la amazonia ha vivido en estrecha armonía con su medio ambiente. Desde un inicio el hombre amazónico se ha servido de sus recursos ecológicos para sobrevivir en un espacio muchas veces crítico y difícil, de su ecología ha tomado todos los elementos necesarios para alimentarse, protegerse, comunicarse. Aunque la inmersión del pensamiento occidental a través de la globalización, está rompiendo con esta concepción armónica de preservación y sostenibilidad. Los preceptos occidentales son más instrumentalistas y utilitarias que rompen con la racionalidad originaria construida por milenios, donde la estrecha relación entre el hombre con su ecología es el principal factor de sobrevivencia de la cultura y la ecología.

La mayoría de la literatura antropológica escrita sobre esta materia, sostienen que las comunidades nativas en la región, han tenido una adaptación milenaria al medio ambiente, que ha redundado en la acumulación de un acervo inmenso y valioso de conocimientos sobre las formas de utilizar los recursos naturales sin destruirlos; practican la horticultura de tumba, quema. La caza y la pesca constituyen su actividad principal compartiendo el producto de estas actividades al interior de los grupos. De acuerdo con una mitología que establece pautas de manejo de estos recursos, evitan destruir las poblaciones de fauna mediante el uso regulado de las mismas.

Quienes conocemos esta región del país, sabemos que la población nativa, del bosque extraen diversos productos utilizados para la construcción de viviendas; productos vegetales y animales para alimentación; elementos rituales (plumas, tinturas, inciensos, bancos ceremoniales, macanas, collares); productos medicinales (anticonceptivos, antiofídicos) y otros. Aseguran su subsistencia a partir de una utilización sostenida y diversificada de los recursos naturales, fundada en un conocimiento de la distribución espacial y oferta temporal de los mismos. En la medida que todavía conservan rasgos fundamentales de su cultura tradicional, garantizan su supervivencia y la conservación del frágil medio ecológico que habitan. Cada una de las familias posee una chacra que es una porción de terreno destinada a la horticultura de tipo itinerante, y en la cual se cultivan productos de sustento. La economía de subsistencia se incrementa con la recolección de frutos y con presas obtenidas en las actividades de caza y pesca.

\subsection{3.- Su cosmovisión ${ }^{225}$}

Las poblaciones nativas de las comunidades amazónicas conciben el mundo centrado en su territorio, en el bosque, como una totalidad compuesta e interrelacionada por elementos como los ríos, lagunas, animales, plantas, sus territorios sin límites, sus costumbres, mitos, leyendas y su religiosidad. Piensan que la naturaleza es una entidad con la cual hay que establecer relaciones armoniosas, de equilibrio y no de dominación que conduce a alterarla en las formas destructivas propias de los colonos, misiones religiosas, empresarios, gobiernos o el Estado.

\footnotetext{
${ }^{225}$ cosmovisión es la manera de ver e interpretar el mundo. Se trata del conjunto de creencias que permiten analizar y reconocer la realidad a partir de la propia existencia. Puede hablarse de la cosmovisión de una persona, una cultura, una época, etc. Una cosmovisión es integral, abarca aspectos de todos los ámbitos de la vida, como la religión, la moral, la filosofía, la política etc.. Las relaciones sociales, la cultura y la educación, resultan claves a la hora del desarrollo de la cosmovisión individual, en tanto que, los seres humanos son seres sociales y, nadie crece aislado y ajeno al entorno.
} 
Analizando metodológicamente los factores que han alterado la naturaleza y la cultura amazónica, podemos afirmar, que su economía se ha basado en la agricultura, en la horticultura, la recolección, la caza, la pesca. La actividad agrícola es diversa, relativa con "roza, quema"226, y con barbecho ${ }^{227}$. Dicha actividad está dividida en tantas partes y momentos como intervenciones o acciones haya realizado el hombre y la mujer.

Esto no se entiende, si no tomamos en cuenta su concepción de propiedad de la tierra o del territorio, piensa que el territorio es libre, sin límites, no es propiedad de nadie, porque nadie tiene derecho de apropiarse de lo que es de todos. No creen en las delimitaciones territoriales con fines agrícolas. De ahí también que se comprenda por qué no estuvieron de acuerdo con las delimitaciones territoriales y agrícolas que se hicieron como producto de la aplicación de la Ley de Comunidades Nativas, aunque esta concepción está variando en los últimos años.

Conciben el trabajo como una relación dirigida a producir los bienes y servicios que sirvan primordialmente para su subsistencia, y también para el comercio si es que sobra excedente. Esta actividad no se mide y valora solamente por los productos sino también por los procesos, es decir, por todo el conjunto de actividades realizados para obtener los productos.

\subsection{4.- La naturaleza, ciencia y tecnología}

El centro fundamental de la naturaleza es el territorio que se expresa en el bosque, integrado por el agua, la flora, la fauna, la tierra, el aire. El ser que determina y justifica la existencia del hombre amazónico es el territorio libre, usufructuado solidaria y colectivamente. Los principios fundamentales que regulan el pensamiento amazónico sobre la naturaleza son la totalidad, unidad, diversidad, e integralidad. La noción de territorio indígena es un concepto que intenta acercarse a definir la realidad milenaria de relación entre los pueblos indígenas y su hábitat natural, así como la ineludible necesidad de respetarla a la hora de asegurar el futuro de cualquiera de los dos términos de esa relación, los territorios y los pueblos indígenas se pertenecen, de ahí su identificación con el "territorio", tal cual ha sido diseñado en el Convenio 069-OIT.

\section{Medicina Herbolaria}

Para los grupos indígenas, la conservación de la biodiversidad es asegurar su propia sobrevivencia. Todas las enfermedades propias de la selva son curadas mediante el uso de tratamientos hechos a partir de elementos de la naturaleza, en su mayoría plantas.

${ }^{226}$ La agricultura de "roza, tumba y quema", se relaciona frecuentemente con la degradación del ambiente. El debate se centra en la idoneidad de este sistema dadas las condiciones ambientales. La fertilidad de los suelos es por lo general reducida, lo que hace imposible lograr cosechas abundantes durante largo tiempo sin fertilizar el suelo. La productividad del suelo se recupera dejando descanse por varios años. Sin embargo, en las últimas décadas la superficie destinada a esta forma de explotación ha crecido considerablemente, mientras que los ciclos de descanso se han acortado. Esto no sólo ha impactado negativamente a la producción sino que representa una amenaza al entorno. El uso del fuego para la agricultura es responsable de un importante número de incendios forestales. Resultado de ello, el suelo de la selva se degrada y numerosas especies típicas de la vegetación madura son incapaces de sobrevivir bajo un régimen de incendios constantes.

${ }^{227}$ Se denomina barbecho a la técnica por la cual la tierra se deja sin sembrar durante uno o varios ciclos vegetativos, con el propósito de recuperar y almacenar materia orgánica y humedad, a que sus ciclos terminen sin poder volver a renovarse debido a la falta de hospederos disponibles. Antes de volverse a cultivar, generalmente se hace limpieza de ésta quitándole las malas hierbas, espinos, malezas etc. 
En diversos estudios etnobotánicos ${ }^{228}$ de reconocidos autores ${ }^{229}$ se ha encontrado, por ejemplo, que las comunidades quichuas ubicados en la vía Hollín-Loreto utilizan 61 especies de plantas con fines medicinales los cofanes de Dureno conocen 292 plantas útiles los quichuas en las faldas del volcán Sumaco utilizan 173 plantas los huaorani utilizan120 plantas los achuar 130 los siona y secoya 224 los quichuas de la cuenca del Río Napo 212 plantas medicinales del pueblo Quichua del Napo.

Autores como Alarcón ${ }^{230}$, encontró que la malaria puede ser tratada con hojas de Verbena littoralis (verbena); el reumatismo y dolores musculares se usan las hojas de hortiga así como de chini-panga (Urera), para problemas de la piel hay una larga lista de plantas que pueden ser utilizadas, incluyendo la hagapania (Ossaea), el tabaco, chiquita payanzo (Miconia), por mencionar unas pocas.

Para la cistitis usan la escobilla (Sidascandis), para las caries dentales se lava los dientes con quihui (Spilanthespaniculata), para las diarreas el palo de sangreoWarscewicziacoccinea, para la holandahuapa o Virola.

La forma como conviven con los distintos elementos de la naturaleza también se basa en el conocimiento que tienen las distintas formas de vida del bosque. Por ejemplo, para las picaduras de hormiga se aplican el látex de Cyclanthusbipartitus (papango). En caso de mordedura de culebra se toma el tubérculo hervido y molido de Xanthosomahelleborifolium (Machacui-yuyo). La planta llamada Chucchuhuatana del género Drymonia, es usado por las mujeres que están dando de lactar para que les aumente la cantidad de leche (Alarcón, 1988).

\section{Regulación jurídica.}

Analizando estos conocimientos de las comunidades nativas, es necesario reformular algunos fundamentos de este proceso que transforma y aprisiona los saberes de las comunidades tradicionales bajo la forma de bienes jurídicos. Además de lo anterior, se pretende describir el movimiento sincrónico de dicha transformación, por medio del cual las comunidades tradicionales que crean ese conocimiento y sean reconocidas por el ordenamiento jurídico, al ser definidas como "nuevos sujetos colectivos de derecho". Los tratados internacionales así lo reconocen.

La regulación jurídica del conocimiento tradicional, transita por la definición simplificadora de nuevos "bienes jurídicos" y, por consiguiente, por el reconocimiento de "nuevos sujetos de derecho". Una de las preocupaciones de este trabajo, consiste en demostrar, que la definición de lo que son o no bienes para el derecho, constituye una elección arbitraria, determinada por un modelo de sociedad determinado. Al ser vinculadas culturas distintas o, si se prefiere, el "conocimiento tradicional" al concepto abstracto de "bien", automáticamente se le confiere a aquellas formas de vida, una serie de caracterizaciones jurídicas particulares, que provienen de la noción jurídica de "bien" o también de "cosa", posibilidad de apropiación. Se genera por tanto, lo que en el campo de la

\footnotetext{
${ }^{228}$ La etnobotánica estudia las relaciones entre los grupos humanos y su entorno vegetal, es decir el uso y aprovechamiento de las plantas en los diferentes espacios culturales y en el tiempo.

${ }^{230}$ Shirif, Alberto (2004) Atlas de las Comunidades Nativas dela Selva. Lima. Centro de Estudios Amazónicos.
} 
filosofía del derecho toma el nombre de ontología del derecho y que es la materia prima del legislador.

Estos conocimientos tradicionales, tienen una fuerza social gravitante en la población nativa, sus miembros, viven inmersos en estos conocimientos, dado que, forma parte de la vivencia humana traducida en la sabiduría popular, que a su vez, ha sido heredada de sus antepasados. Estos conocimientos, sirvieron de base para que los especialistas en medicina tradicional, obtuvieran resultados en base a la extracción de plantas, raíces y cortezas para producir productos medicinales que se expenden en el mercado.

También, fueron apropiados ilícitamente por agentes externos. Más aún, han sido registrados como si fueran propios. Estos hechos, han sido tenidos en cuenta para que tanto en la Ronda de Uruguay, como en Marraquech fueran debidamente reguladas conforme veremos más adelante.

\subsection{5.- Familias etnolingüísticas y grupos étnicos en la Amazonía Peruana ${ }^{231}$}

Pasemos una vista panorámica de algunas comunidades nativas, que, por su importancia nacional, revive el espectro nativo. Para hacer esta somera visión general, se tuvo que recurrir a una frondosa bibliografía existente y proporcionada por ONG, Institutos de Investigaciones amazónicas, así como escritos de Antropólogos especialistas en esta literatura $^{232}$. Según los censos nacionales, la población alcanza más de un millón de habitantes; sin embargo, aquí presentamos un grupo de familias de un universo de dos a tres comunidades nativas.

\section{Los Bora}

Los indígenas Bora mantienen zonas de bosque permanente, dentro de sus agro ecosistemas. Las zonas con bosques cubren áreas que se inundan estacionalmente y siguen los arroyos que comúnmente separan las chacras. Se conservan debido a las especies útiles que se encuentran en estas zonas bajas, y también porque estas áreas no se consideran buenas para el cultivo de yuca. Las áreas con bosques se cosechan frutos, madera, animales de caza. Ponen mucha atención en los lugares y en el crecimiento de algunos árboles en particular.

${ }^{231}$ Instituto del Bien Común (IBC). Viene desarrollando desde 1998 el Sistema de Información sobre Comunidades Nativas de la Amazonía Peruana (SICNA), cuya información está georreferenciada en el campo y abarca el $80 \%$ de las comunidades existentes. El 20\% restante de la información sobre comunidades que se incluye en los mapas ha sido georreferenciada en gabinete o aún debe ser verificada en el campo. El número de comunidades y hectáreas tituladas/demarcadas que figura en los cuadros y mapas puede aumentar en el futuro debido a la obtención de nuevos registros en el campo o a la creación y/o titulación de nuevas comunidades. El IBC agradece a las instituciones que han aportado información al SICNA, las cuales figuran en las fuentes y fichas técnicas, así como a las organizaciones indígenas que han colaborado con el levantamiento de información. El IBC ofrece esta publicación como una contribución al desarrollo sostenible de la Amazonía, a la conservación de sus bosques y biodiversidad y al respeto a los territorios y derechos de los pueblos indígenas

${ }^{232}$ Entre las Instituciones del que se obtuvieron la información necesaria están: el Instituto de Bien Común, en coordinación con el Instituto de Recursos Mundiales, crea el Sistema de Información de la Amazonía Peruana (SICNA); Centro Cultural José Pío Aza; servicios en Comunicación Intercultural (Servindi) que presentó el Atlas de Comunidades Nativas de la Selva Central; Adrián Mendoza Ocampo (2001) Comunidades Nativas: El espíritu Milenario de la Selva, visión etnográfica.; Libros Andinos, Atlas delas Comunidades Nativas dela Selva Central; Ministerio del Ambiente; Real Instituto Elcano; Cofropi-Perú, Organismo de formalización de la propiedad informal. 


\section{Los Machiguenga}

Debido al gran territorio que manejan, los Machiguenga tienen más de un cultivo a la vez. Tienen una producción de calorías muy alta, pero el consumo es mucho más bajo lo que les permite una autonomía familiar. El maíz es una prioridad. Se cultiva en campos recién abiertos. Para sembrar hacen huecos con estacas de palma, después del maíz siembran yuca, los que representan el $85 \%$ de lo que cultivan. El resto son 18 productos de menor importancia. Por vivir en un ecosistema montañoso, manejan altitudinalmente el terreno. El maíz es más propicio en este tipo de suelos.

\section{Los Amuesha}

Las diferencias altitudinales en las que habitan los Amuesha, no permiten el manejo del suelo y espacio mediante jardines o parcelas policultivadas porque la heterogeneidad climática, topográfica y de suelos dificulta establecer asociaciones; dividen el territorio según su morfología de donde se desprende la vocación de sus suelos. Cada área tiene una vocación de cultivo y cada familia debe combinar el espacio disponible a lo largo de todo el año para asegurar el suministro de alimentos.

En las tierras bajas tienen árboles maderables. En las tierras altas -bajas cultivan maíz y palmas. En las playas de los ríos cultivan fréjol. En las islas, maíz y Erythrina. En los pantanos las palmas aguaje y Mauritia. En las tierras de altura con suelos rojos cultivan arroz, yuca y árboles frutales. En áreas con arenas blancas el caucho y de arenas amarilla, el barbasco y balsa. En zonas de suelos negros cultivan maíz y árboles maderables.

\section{Los Chamicuro}

La principal actividad para la subsistencia de los chamicuros es la horticultura de roza y quema, y los principales productos son la yuca, plátano, maíz, maní, camote, habas, taro, calabazas y tabaco. La caza y la pesca son también importantes para la subsistencia, y se ha extendido entre las familias de este grupo la crianza de aves y animales menores como fuente complementaria de proteínas. El arroz, el yute, el maní, el maíz, el plátano y la yuca son comercializados por ellos en el poblado de Lagunas o vendidos a los regatones que transitan por la comunidad. Extraen madera de manera individual con fines comerciales y entregan la producción a los patrones.

\section{Los Chayahuita}

Ubicado entre los ocho grupos indígenas más importantes desde el punto de vista demográfico, los Chayahuita con sus 13717 personas empadronadas, constituyen 5,72\% de la población indígena censada. La información censal revela la existencia de un volumen poblacional para este grupo que supera en más del ciento por ciento las estimaciones demográficas más optimistas que se habían señalado hasta 1978. En la actualidad, la economía de los Chayahuita depende de la agricultura de roza y quema, la caza y la pesca. Los principales cultivos de sus huertos son la yuca, el plátano, el maíz, el frijol, el maní, el arroz, la piña, la papaya, el algodón y el tabaco. 


\section{Los Harakmbut}

Este conjunto Harakmbut comprende varios pequeños grupos: Amarakaeri, arasaeri, huachipaeri, kisamberi, pukirieri, sapiteri y toyoeri. Ha registrado un total de 1623 personas, que representa únicamente $0,67 \%$ del total de la población indígena censada.

Por ser el Amarakaeri el grupo demográficamente dominante y conocido en la literatura antropológica bajo esa denominación, se optó por asumir ese nombre para identificar a la población Harakmbut. Se encuentran organizados en siete clanes o patrilinajes localizados. La norma ideal de matrimonio es el intercambio de hermanas entre dos clanes, dándose dicha relación de intercambio entre los siete clanes. Así cada clan puede intercambiar mujeres con los seis restantes. Esto guarda coherencia con la terminología de parentesco de tipo dravidio, según la cual son parientes consanguíneos los miembros del propio clan y son parientes afines teóricamente los seis clanes restantes.

\section{Los Huambisa}

Los huambisas practican la agricultura de subsistencia, la caza, la pesca y la cría de aves de corral. Este grupo relativamente numeroso y con un alto nivel organizativo se encuentra ubicado en un área de exploración de hidrocarburos y de frontera política en situación de conflicto, y puede considerársele en una situación de media vulnerabilidad.

\section{Los Amahuaca-Yora}

Con una población censada de 247 personas, los Amahuaca representan apenas 0,10\% de la población indígena censada. Se estima una importante omisión en el registro de la población Amahuaca, debido probablemente a su nivel de dispersión y aislamiento, sufrieron considerables estragos desde el punto de vista demográfico durante el denominado "boom" del caucho, cuando epidemias severas redujeron sensiblemente su población. Por su reducida población, carencia de servicios básicos, particularmente de salud, y exploración petrolera en curso, la situación de este grupo altamente disperso es de alta vulnerabilidad.

\section{Los Cashibo-Cacataibo}

En 1993, se censó un total de 1661 personas como integrantes de este grupo indígena, lo que representa $0,69 \%$ sobre el total de la población indígena censada. Las estimaciones poblacionales anteriores a este censo, ubicaban entre 1000 y 2250 los límites mínimos y máximos de la población Cashibo-Cacataibo.

Esta sociedad se encuentra organizada en grupos patrilineales y patrilocales. La sociedad está dividida en un ámbito de consanguíneos y otro de afines por medio de una terminología de parentesco de tipo dravidia. El modelo ideal de matrimonio es el de casamiento simétrico de primos cruzados, dándose así el intercambio de hermanas entre dos grupos. Así, dos grupos de descendencia intercambian mujeres. Existe la regla de servicio del yerno, quien tras su casamiento deberá permanecer durante el primero a segundo año en la casa de su suegro, tras lo cual la pareja pasa a residir con la familia del esposo. 


\section{Los Yagua-Yihamwo}

Mantenían relaciones asimétricas con los Omaguas de quienes eran servidores domésticos y esclavos. A la llegada de los jesuitas, las misiones se convierten en zonas de refugio para los indígenas perseguidos por los "bandeirantes" ${ }^{233}$ esclavistas. Inicialmente hostiles a las misiones, mayoritariamente pobladas por Omaguas, ante la amenaza de los "bandeirantes", los yaguas finalmente buscaron la protección de los misioneros. Sin embargo, las epidemias que periódicamente se desataban en las reducciones llevaron a mutuas acusaciones de brujería entre los grupos que en ellas habitaban produciéndose guerras.

Están divididas en clanes patrilineales. La regla de residencia post-matrimonial es patrilocal. Los diferentes clanes se encuentran asociados a nombres de aves, de vegetales o de animales terrestres. Estas tres categorías naturales en las que se encuentran agrupados los clanes son, a su vez, organizadas según un modelo de mitades exógamas. Este puede ser de intercambio entre los clanes de las aves por un lado y de los vegetales y animales terrestres por otro.

\section{IV.- Análisis e interpretación}

Con la información presentada, en la parte tercera, voy a trabajar con el aspecto metodológico que a partir de aquí, se constituye en la herramienta principal en todo proceso de investigación. En primer lugar analizaré el inciso c) del artículo $\mathbf{1 0}$ del Convenio de la Diversidad Biológica (CDB), utilizando los elementos metodológicos formulados, ellos son: el objeto a) del estudio y la hipótesis 2.3.1.- Esta fórmula es muy importante, puesto que, debe guardar coherencia entre lo que se pretende obtener (objeto del estudio) y lo que se desea demostrar (hipótesis). Además del texto del convenio existen otros documentos muy importantes que han sido suscritos como complementos del mismo, esto enriquece el análisis conforme lo demostraré más adelante; se adjuntará los soportes legales como prueba de la hipótesis y medir de paso, la capacidad de las instituciones de atender a este problema.

\section{1.- "Artículo 10. Utilización sostenible de los componentes de la diversidad} biológica". Inciso c):

"Cada Parte Contratante, en la medida de lo posible y según proceda":

Inciso c": Protegerá y alentará la utilización consuetudinaria de los recursos biológicos, de conformidad con las prácticas culturales tradicionales que sean compatibles con las exigencias de la conservación o de la utilización sostenible".

\section{Sustentos:}

\section{Objeto del estudio:}

a. Explicar las formas de conservación de la diversidad biológica en las Comunidades Nativas de la Amazonía peruana mediante los sistemas ancestrales.

Hipótesis.2.3.1.- Las comunidades nativas de la Amazonía peruana conservan desde tiempos ancestrales su diversidad biológica, haciendo uso adecuado de la flora $y$ fauna para el sustento familiar.

${ }^{233}$ La literatura antropológica hace referencia a los "bandeirantes brasileños", que se dedicaban al tráfico de esclavos, apresar indios y hallar metales preciosos. 


\subsection{1.- Comprobación de la hipótesis. El sustento}

Muchos autores y estudiosos en la materia, han explicado con meridiana claridad el uso sustentable de la diversidad biológica en concordancia con uno de los tres objetivos del Convenio, que lo define como "la utilización de los componentes de la diversidad biológica de un modo y a un ritmo que no ocasione la disminución a largo plazo de la diversidad biológica con lo cual se mantienen las posibilidades de ésta de satisfacer las necesidades y aspiraciones de las generaciones actuales y futuras ${ }^{234}$." El uso sustentable de la diversidad biológica promueve su conservación, ya que, en muchos casos, ofrece incentivos para la conservación y la restauración por los beneficios sociales, culturales y económicos que la gente obtiene de ese uso.

Por otro lado, es posible hacer uso racional de la diversidad biológica, de los procesos ecológicos, las especies, a fin de que la variedad genética se mantengan por encima de los umbrales necesarios para su viabilidad a largo plazo y que, por consiguiente, todos los administradores y usuarios de estos recursos, tengan el deber de asegurarse que no excede de estas capacidades. Es por tanto, mantener la diversidad biológica en los ecosistemas, o incluso regenerarla ocasionalmente, para garantizar que éstos tengan la capacidad de sostener los servicios ecológicos de los que dependen tanto la diversidad biológica como los seres humanos.

Las prácticas tradicionales del uso de la diversidad biológica de las comunidades nativas de la Amazonía peruana, guardan relación con el conocimiento tradicional y el reconocimiento de la importancia de la biodiversidad conforme hemos visto en el marco geográfico, sustentada también en el principio 12 de las Directrices de Addis Abeba ${ }^{235}$ que a la letra dice: "Principio práctico 12: Las necesidades de las comunidades indígenas y locales que viven de la utilización y la conservación de la diversidad biológica, y que se ven afectadas por éstas, deben reflejarse, junto con sus contribuciones a esta conservación y utilización sostenible, en la participación equitativa en los beneficios que se derivan del uso de esos recursos".

Los motivos que dieron lugar a este principio se señala con frecuencia, son las comunidades indígenas, grupos locales e interesados directos, que asumen costos importantes o se privan de los beneficios del uso potencial de la diversidad biológica a fin de garantizar o mejorar los beneficios que otros acumulan. Muchos recursos (por ejemplo, la madera, la pesca) están excesivamente explotados porque las reglamentaciones se ignoran y no se hacen cumplir; cuando la población local participa como interesada directa, disminuye en general estas explotaciones.

Los regímenes de gestión se mejoran cuando se aplican programas constructivos que benefician a las comunidades locales, como instrucción para capacidades que pueden ofrecer alternativas de ingresos o asistencia en la diversificación de sus capacidades de gestión señalando las directrices operacionales como: "promover incentivos económicos que garantizarán beneficios adicionales para las comunidades indígenas y locales y los interesados directos que participan en la gestión de cualquier componente de la diversidad

\footnotetext{
${ }^{234}$ Artículo 2 del Convenio de la Diversidad Biológica.

${ }^{235}$ Secretaría del Convenio sobre Diversidad Biológica (CDB), N.U.,Y PNUMA (2004) "Principios y Directrices de Addis Abeba para la Utilización Sostenible de la Diversidad Biológica” Documento, Montreal..
} 
biológica, por ejemplo, oportunidades de empleo para la gente local, igual distribución de los ingresos entre los habitantes locales, inversionistas y coadministradores foráneos" 236 Veamos lo que sucede en las Comunidades Nativas de nuestra Amazonía. La biodiversidad es muy rica en esta zona, prestemos atención en las imágenes:
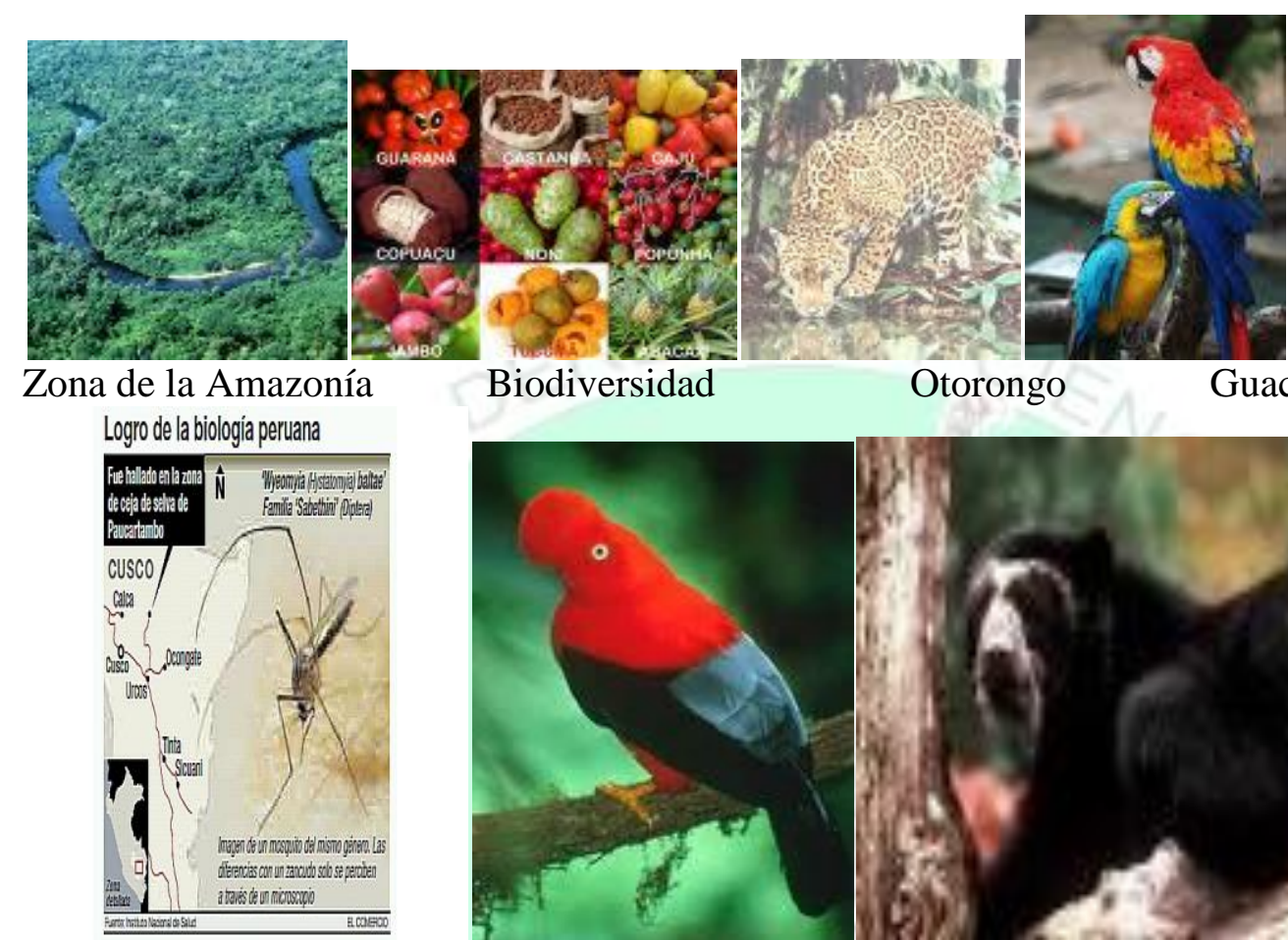

Biodiversidad

Otorongo

Guacamayos
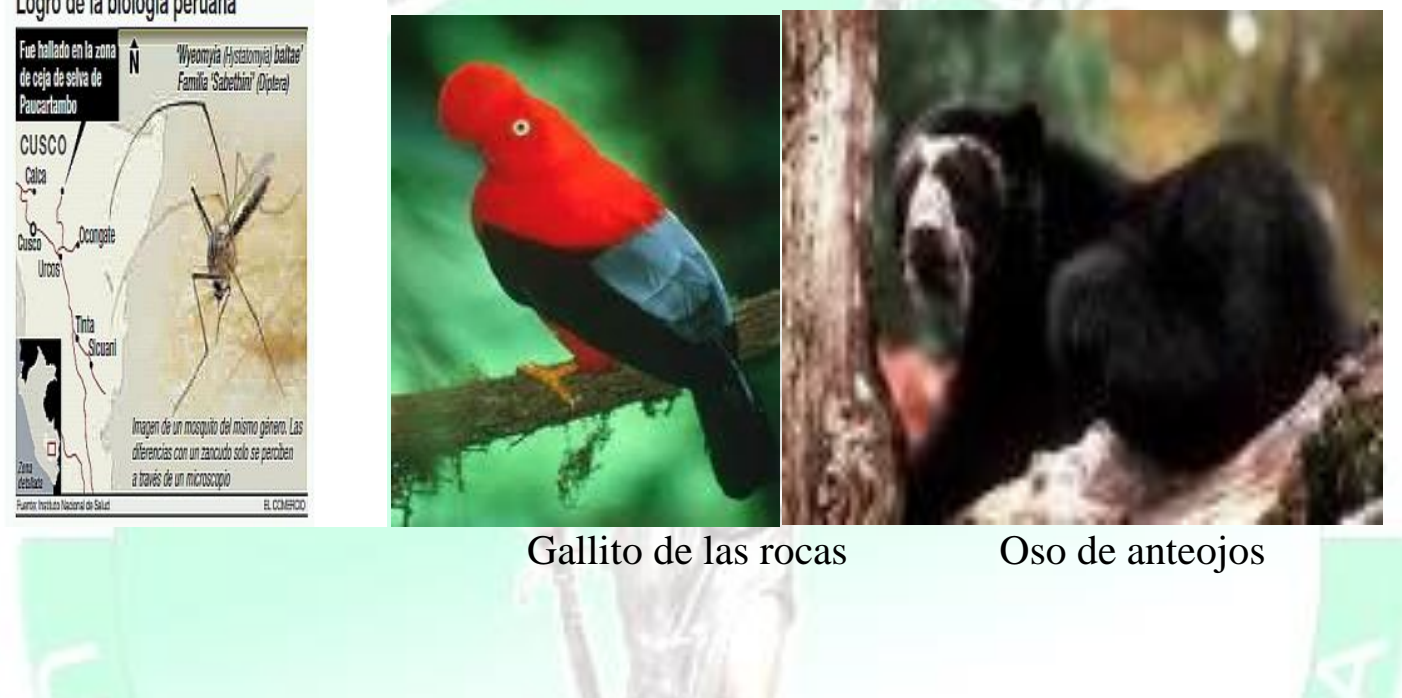

Los ríos de la Amazonía peruana dan una imagen serpenteada que discurren sus aguas al río más grande del mundo -el amazonas - los frondosos árboles ahí existentes, forma parte del pulmón de la humanidad, es muy rica en madera de alta calidad, las que se constituyen en preciosas riquezas para los extractores. En base de la explotación de esta especie, se constituyeron empresas madereras que lo comercializaron tanto al mercado nacional como al internacional. Usurparon la riqueza de las comunidades nativas, éstas, conscientes o inconscientes contribuyeron a su depredación, talándolas para vender a estas empresas, recibiendo como compensación, pagos irrisorios, lo que aumentaba el capital de estas empresas monopólicas. No existían mayor control, de ahí que, gran parte de los bosques con árboles maderables como el pino, cedro, caoba entre otros, se constituyeron como los mejores para la fábrica de todo tipo de muebles.

La fauna silvestre, tal como apreciamos en las imágines, es diversa, el gallito de las rocas es el ave representativa del Perú. El oso de anteojos, los guacamayos y otras aves, se encuentran en procesos de extinción por la caza furtiva, igual sucede con otras especies como los paiches y las araguanas, estas últimas la podemos encontrar en los ríos de la selva peruana, muy apreciada la primera por su carne y la segunda por su exportación como peces ornamentales. Por tanto, es urgentes medidas de protección.

\footnotetext{
${ }^{236}$ Secretaría del Convenio Sobre Diversidad Biológica, op.cit., p. 19.
} 
La Amazonía peruana es muy rica en biodiversidad, es el lugar donde se producen y reproducen toda especie propia de esta zona; sin embargo, la cultura tradicional conforme hemos visto en la primera parte, hace esquiva a dichos procesos. La rutina en la extracción de la madera por parte de empresas dedicada a su comercialización, hace de esta zona, que la variabilidad biológica vaya modificándose, tanto por la presencia de comercializadores de dicho producto, como por otros factores, como la compra de dichas especies a los propios nativos.

La caza es una actividad principal de las comunidades nativas y sirve también para su sustento; sin embargo, ellos saben valorar especies que se encuentran en estado de extinción como el "gallito delas rocas" que ha sido considerado por el gobierno como el "ave representativa" de la selva peruana, el "oso de anteojos" muy cotizado por los depredadores y cazadores furtivos. En lo referente a la agricultura, las comunidades nativas, si bien es cierto que aún mantienen sus prácticas ancestrales, están siendo modificadas por nuevas formas de cultivo con ayuda de organismos nacionales como ONG, misioneros de las iglesias así como por el Estado mediante el asesoramiento de organismos del Ministerio de Agricultura.

En lo referente al conocimiento tradicional que es el saber culturalmente compartido y común a todos los miembros que pertenecen a una misma sociedad, grupo o pueblo, y que permite la aplicación de los recursos del entorno natural de modo directo, compuesto, combinado, derivado o refinado, para la satisfacción de necesidades humanas ${ }^{237}$. Las comunidades poseen un conocimiento milenario sobre el uso y manejo de los recursos naturales. La coexistencia de las comunidades indígenas y los bosques tropicales de la región, ha sido claramente documentada, haciendo referencia al manejo de los recursos y a la custodia de los bosques, por las poblaciones indígenas de acuerdo a su cosmovisión.

Sin embargo, estos conocimientos han sido vilmente utilizados por empresas foráneas a la realidad de dichas comunidades, dando lugar a que éstos fueran protegidos por organismos internacionales como la $\mathrm{OMPI}^{238}$. Antes de analizar este documento, veamos la riqueza de estos conocimientos en la Amazonía peruana ${ }^{239}$.

Los conocimientos tradicionales de las plantas y su uso surgen de las personas mayores de la comunidad, los longevos y son los que poseen tradicionalmente estos conocimientos. No es posible realizar un estudio de las plantas sin consultar a los ancianos, es importante que se conserven las culturas tradicionales mediante la educación, para así asegurar la continuidad de la transferencia de los conocimientos tradicionales de una generación a otra en beneficio de la humanidad. Las relaciones colectivas e individuales, los sistemas familiares, las instituciones sociales, la justicia tradicional, la música, bailes, ceremonias, rituales, deportes, idiomas, literatura, mitología, historias, nombres, recursos terrestres, marítimos y aéreos están conectados intrínsecamente a la naturaleza, que revela la relación de los seres humanos con las plantas y animales. Esta relación se extiende al entorno físico y al universo cósmico. Una relación de este tipo se expresa en rituales tradicionales, en

${ }^{237}$ ZAMUDIO, Teodora (2003) Pro Diversitas, a.c.

${ }^{238}$ OMPI (2001). Conocimientos Tradicionales: Necesidades y Expectativas en Materia de Propiedad Intelectual. "Informe relativo a las misiones exploratorias sobre propiedad intelectual y conocimientos tradicionales", Ginebra.

${ }^{239}$ Cip (Centro de Documentación, Investigación e Información de los Pueblos Indígenas). Con motivo de su XX aniversario se llevó a cabo en Ginebra Tres días de práctica e intercambio sobre el tema de los saberes tradicionales y los conocimientos científicos para un desarrollo sostenible del que extraemos algunas conclusiones 
los que se utilizan, plantas y animales, que se presentan como ofrendas al universo cósmico para conservar la naturaleza al servicio del hombre.

En lo que a conocimiento científico y uso de plantas se refiere, las comunidades indígenas y locales saben diferenciar entre un uso benigno y otro dañino para ellos. Esta habilidad proviene de su capacidad para reconocer los ciclos de vida naturales. La sociedad civil, por tanto, debe estar alerta para evitar que la ciencia y las grandes empresas, no pongan en peligro los ciclos naturales. El conocimiento tradicional es parte de la cultura tradicional, representan un elemento básico del ecosistema. Cuando se pone en peligro o se amenaza la biodiversidad, las plantas se ven afectadas. En algún momento, una destrucción de este tipo destruirá los conocimientos tradicionales y, en última instancia, a la humanidad.

Hoy, la comunidad internacional reconoce el papel y la importancia de los conocimientos tradicionales y de las prácticas de gestión tradicional para lograr un desarrollo sostenido. Algunos instrumentos internacionales, como la Convención sobre Diversidad Biológica (CBD) y la convención Ramsar ${ }^{240}$ sobre pantanos, han creado un marco para tener en cuenta las prácticas de gestión tradicional y la participación de las comunidades indígenas para la gestión de los recursos.

De conformidad con estos planteamientos, veamos ahora los avances en cuanto a la participación del Estado sobre la protección de dichos recursos:

\section{La protección.Legislación Nacional}

En 1999 el gobierno emite la ley № 27811 que establece el régimen de protección de los conocimientos colectivos de los pueblos indígenas vinculados a los recursos biológicos. $\mathrm{Su}$ artículo 23 reconoce la importancia y el valor de los conocimientos, innovaciones y prácticas de las comunidades campesinas y nativas, para la conservación y utilización sostenible de la diversidad biológica. Asimismo, se reconoce la necesidad de proteger estos conocimientos y establecer mecanismos para promover su utilización con el consentimiento informado de dichas comunidades, garantizando la distribución justa y equitativa de los beneficios derivados de su utilización.

La intención del legislador es buena al sostener "el conocimiento informado", es decir, cualquier forma de apropiación del conocimiento tradicional, sea esta en el tratamiento de plantas medicinales u otras formas, deberían ser consultadas con la población nativa. Esto se hacía con la finalidad de evitar una forma vil de "apropiación" de dichos conocimientos, por agentes externos que se apropiaban ilícitamente, "patentándolos" como si fueran de ellos, esto dio lugar a reclamos y a presentar recursos ante los organismos internacionales a fin de que anulen estas patentes.

\footnotetext{
${ }^{240}$ El Convenio de Ramsar, o Convención relativa a los Humedales de Importancia Internacional especialmente como Hábitats de Aves Acuáticas, fue firmado en la ciudad de Ramsar, Irán, el 2 de febrero de 1971 y entró en vigor en 1975. Este acuerdo internacional es el único de los modernos convenios en materia de medio ambiente que se centra en un ecosistema específico, los humedales, y aunque en origen su principal objetivo estaba orientado a la conservación y uso racional en relación a las aves acuáticas, actualmente reconoce la importancia de estos ecosistemas como fundamentales en la conservación global y el uso sostenible de la biodiversidad, con importantes funciones y atributos (refugio de diversidad biológica, patrimonio cultural, usos tradicionales).
} 
Por otro lado, su artículo 24 reconoce que los conocimientos, innovaciones y prácticas de las comunidades campesinas, nativas y locales asociados a la diversidad biológica, constituyen "patrimonio cultural" de las mismas, por ello, tienen derecho sobre ellos y la facultad de decidir respecto a su utilización.

El término patrimonio cultural, implica la importancia que tiene para el Estado y para las comunidades, los conocimientos producidos por ellos mismos y la importancia que éste tiene en relación con la identidad nacional, su conservación para el futuro de las generaciones, evitando todo tipo de depredación. Por esto se justifica el conjunto de normas que emite el Estado.

En el 2002, el gobierno peruano promulga le ley $N^{\circ} 27811$ que establece el régimen de protección de los conocimientos colectivos de los pueblos indígenas vinculados a los recursos biológicos. El artículo primero señala: "El Estado peruano reconoce el derecho y la facultad de los pueblos y comunidades indígenas de decidir sobre sus conocimientos colectivos".

Más adelante, su artículo $42^{\circ}$.- señala la forma de protección, al sostener que "el pueblo indígena que posea un conocimiento colectivo estará protegido contra la revelación, adquisición o uso de tal conocimiento colectivo sin su consentimiento y de manera desleal, en la medida en que este conocimiento colectivo no se encuentre en el dominio público. Asimismo, estará protegido contra la divulgación sin autorización en caso de que un tercero haya tenido acceso legítimamente al conocimiento colectivo pero con deber de reserva".

Por tanto, no solo las comunidades nativas de la amazonia peruana preservan su ecología desde tiempos inmemoriales, sino también el Estado ha cumplido con su deber de protegerlos. El espíritu de la norma es bueno. Veamos su cumplimiento.

\section{El cumplimiento}

En el Perú existen cuarenta y dos áreas naturales protegidas ${ }^{241}$ que cubren un total aproximado de ciento veinte y siete mil kilómetros cuadrados, lo que corresponde al 4,3\% de la superficie del país. De acuerdo a sus objetivos y tamaño, existen tres categorías de áreas naturales: zonas intangibles, zonas de uso controlado y zonas reservadas. Las zonas intangibles son aquellas en las que se prohíbe todo uso directo de los recursos y en las que sólo se permite realizar investigación científica y turismo controlado, como parques nacionales, santuarios nacionales y santuarios históricos. Dentro de las zonas de uso controlado se encuentran las reservas nacionales, reservas comunales y cotos de caza, y son aquellas áreas en las que se aprovecha la fauna silvestre de manera sostenida, bajo la supervisión del Estado. Por último, las zonas reservadas, son aquellas áreas que están temporalmente protegidas mientras se define su categoría de uso más apropiada.

Así mismo, el Estado mediante los organismos descentralizados, ha convenido asegurar su cumplimiento destinando para ello, presupuesto para equipos y personal encargados de su vigilancia; de esta forma, existe -aunque de manera limitada- los policías forestales y los "guarda parques", este último en la selva, en las llamadas zonas de reservas, tales son los casos de las zonas protegidas de Güeppí, que por su extensión, protege a las comunidades de Kewchas, Huitotos y otras comunidades. También se está organizando a la

${ }^{241}$ Ministerio de Comercio Exterior y Turismo (Mincetur). 
población nativa, para que participen en esta tarea. A pesar de ello, resulta insuficiente para cubrir todo el territorio señalado. Los continuos depredadores de maderas y de recursos ictiológicos, se hacen presentes en estos lugares. La norma está dictada, su cumplimiento estricto falta.

Las zonas intangibles, merece especial atención por parte del Estado; el caso de "Pacaya-Samiria" que cubre una inmensa región de la selva, hoy se ha convertido en centros de visita turística que benefician a empresas de esta naturaleza, con recursos y beneficios para los nativos de la selva. Sin embargo, la participación de la población en los ingresos por estos rubros, todavía se consideran inalcanzables, por cuanto, las comunidades carecen de la infraestructura necesaria. En este punto, se debe revisar la legislación.

Otro punto discordante, es la presencia de empresas petroleras que han adquirido derechos de exploración y explotación del petróleo y el gas. Los líderes de estas comunidades, no están de acuerdo con su presencia, de ahí que, su organización social y política se manifieste en contra de estos proyectos. Han habido casos ya de enfrentamientos con resultados dolorosos.

La legislación es buena, su cumplimiento es mediatizado por una serie de acciones de los encargados de hacerlo cumplir. Si agregamos a ello la falta de equipamiento y pertrechos, llegamos a la conclusión, que la corrupción es el peor mal que aqueja a la población encargada de hacer cumplir estas normas.

Las zonas de "uso controlado" donde se aprovecha la fauna silvestre de forma sostenida, es quizá donde mayor depredación existe todavía, a pesar del control por parte del Estado. Pongo a consideración un solo caso: la depredación del "paiche". Este pez existen en las cochas y ríos que forman parte del territorio de las comunidades nativas, esta especie sufrió un proceso de depredación por parte de empresas hoteleras, la comercialización de este producto se hizo sin discriminación alguna. Los nativos de estas comunidades, al solo hecho de ver la presencia de estos depredadores que llegaban con armas de fuego, se retiraban selva adentro. Para evitar estas acciones de exterminio del paiche, ahora la población nativa, se está organizando y controlando su producción.

Toca ahora revisar brevemente las directrices internacionales que sobre la materia ha sido acordado y aceptado por los Estados. Debemos poner especial énfasis en sus objetivos, sobre todo, en lo concerniente a las comunidades nativas de la amazonia. Veamos:

\section{Legislación Internacional: Directrices de Bonn ${ }^{242}$.}

Las directrices están concebidas para ayudar a las Partes en la elaboración de una estrategia general de acceso y distribución de beneficios, la cual puede formar parte de su estrategia y plan de acción nacionales sobre diversidad biológica, en la determinación de las

${ }^{242}$ Secretaría del Convenio sobre Diversidad Biológica. PNUMA (2002) Canadá. Las directrices identifican los pasos en el proceso de acceso y participación en losbeneficios, haciendo hincapié en la obligación de los usuarios de buscar el consentimientoprevio de los proveedores. Éstas también identifican los requisitos fundamentales para lostérminos acordados mutuamente y definen los principales papeles y responsabilidades delos usuarios y proveedores y destacan la importancia de la implicación de todos losinteresados.Además, éstas cubren otros elementos tales como incentivos, responsabilidad, medios para la verificación y solución de controversias. Finalmente, ellas enumeranelementos sugeridos para incluir en acuerdos de transferencia material y proporcionan unalista indicativa de beneficios tanto monetarios como no monetarios. 
etapas en el proceso de obtener acceso a los recursos genéticos y a la distribución de los beneficios.

Son muchos sus objetivos, lo que interesa al presente estudio son:"promover la transferencia adecuada y efectiva de la tecnología apropiada a las Partes proveedoras, a los interesados y a las comunidades indígenas y locales"; "contribuir a que las Partes desarrollen los mecanismos y los regímenes de acceso y distribución de beneficios en los que se reconozcan y protejan los conocimientos, innovaciones y prácticas de las comunidades indígenas y locales, de conformidad con sus leyes nacionales y con los instrumentos internacionales pertinentes"; "contribuir a la mitigación de la pobreza y prestar apoyo a convertir en realidad la seguridad de los alimentos, la salud humana y la integridad cultural $^{, 243}$.

Correcto, la trasferencia de la tecnología adecuada a las comunidades nativas de la Amazonía peruana, es un reto para el Estado. Tradicionalmente, estas comunidades están regidas por formas de vida que han heredado de sus ancestros, cualquier innovación, si bien es cierto podría calar profundamente en ellos, esto tardaría, en cuanto, no existe todavía la infraestructura necesaria ni el personal para que se profundice esta innovación. Queda como un reto, como un hito diseñado para el futuro; sin embargo, algunos gobiernos regionales lo están intentando, sobre todo, en el manejo de los recursos forestales, ictiológicos y de caza.

Existe el compromiso de muchos miembros de las comunidades nativas de participar en seminarios de capacitación a fin de conocer estos procesos de innovación, pero ahí se quedan. No hay un proceso de continuidad, el peor enemigo es la carencia de medios de transporte, donde los ríos, son los únicos que sirven para el traslado de los miembros de estas comunidades. Agregamos a ello, factores externos, como la posible explotación del petróleo y el gas, concesionado por los Estados. He aquí la incertidumbre.

Podemos "mitigar" la pobreza, tal como vemos en uno de los objetivos, si; pero esto no basta, la transferencia debe serreal y equitativa, hay que dar una efectiva participación a la población nativa, evitemos toda forma de explotación, reconozcamos el valor intrínseco de los recursos y de la población como agentes de cambio, valoremos sus formas de transmitir conocimiento y enriquezcamos su calidad de vida y su cultura, partamos por mejorar la educación respetando su conocimiento tradicional, logremos una mayor participación en toda forma de producción, industrialización y comercialización.

\section{Organización Mundial de la Propiedad Intelectual (OMPI)}

Para la Ompi el término "conocimientos tradicionales" es uno de varios utilizados para describir en términos generales el mismo objeto. Otros términos en uso incluyen la "propiedad intelectual y cultural indígena", el "patrimonio indígena" y los "derechos de patrimonio de acuerdo con los usos y las costumbres". La OMPI utiliza actualmente el término "conocimientos tradicionales" para referirse a las obras literarias, artísticas o científicas basadas en la tradición; así como las interpretaciones o ejecuciones; invenciones; descubrimientos científicos; dibujos o modelos; marcas, nombres y símbolos; información no divulgada y todas las demás innovaciones y creaciones basadas en la tradición que proceden de la actividad intelectual en el ámbito industrial, científico, literario o artístico.

${ }^{243}$ Secretaría del CDB. PNUMA (2002) Directrices de Bonn sobre Acceso a los Recursos Genéticos y Participación Justa y Equitativa en los Beneficios Provenientes de su Utilización p.3. 
La expresión "basadas en la tradición" se refiere a los sistemas de conocimiento, creaciones, innovaciones y expresiones culturales que: se han transmitido generalmente de generación en generación; se considera generalmente que pertenecen a un pueblo en particular o a su territorio, y evolucionan constantemente en respuesta a los cambios que se producen en su entorno.

"Conocimientos tradicionales" es un término que se utiliza únicamente a efectos prácticos. La OMPI reconoce el derecho de los grupos indígenas, las comunidades locales y otros titulares de conocimientos tradicionales a decidir qué constituyen sus propios conocimientos, innovaciones, culturas y prácticas, así como las maneras en que deberían definirse. Entre las categorías de conocimientos tradicionales figuran: los conocimientos agrícolas; los conocimientos científicos; los conocimientos técnicos; los conocimientos ecológicos; los conocimientos medicinales, incluidos las medicinas y los remedios conexos; los conocimientos relacionados con la diversidad biológica; las "expresiones del folclore" en forma de música, baile, canción, artesanía, dibujos y modelos, historias y obras de arte; elementos de los idiomas, como los nombres, indicaciones geográficas y símbolos, y bienes culturales muebles.

Quedarían excluidos de esta descripción de los conocimientos tradicionales los elementos que no se derivan de la actividad intelectual en el ámbito industrial, científico, literario o artístico, como los restos humanos, los idiomas en general y otros elementos similares del "patrimonio" en un sentido amplio.

La legislación peruana haciendo eco de los fundamentos de la Ompi, ha creado el Instituto Nacional de Defensa de la Competencia y de la Protección de la Propiedad Intelectual, conocido también como Indecopi, fue creado en noviembre de 1992, mediante el Decreto Ley $\mathrm{N}^{\circ}$ 25868. Es un organismo público especializado adscrito a la Presidencia del Consejo de Ministros, con personería jurídica de derecho público, es el organismo encargado de la aplicación de las normas legales destinadas a proteger el mercado, de las prácticas monopólicas que resulten controlistas y restrictivas de la competencia en la producción y comercialización de bienes y en la prestación de servicios, así como de las prácticas que generan competencia desleal y de aquellas que afectan a los agentes del mercado y a los consumidores. los derechos de propiedad intelectual, desde los signos distintivos y los derechos de autor hasta las patentes y la biotecnología.La calidad de los productos.Las demás funciones que se le asignen.

Ahora bien, los casos que hayan presentado ante este organismo regulador respecto a los conocimientos tradicionales de las comunidades nativas de la selva, han sido ínfimos, por cuanto, algunas formas de apropiación ya habían sido patentadas, tal es el caso de la "uña de gato Schuler" que se comercializa en los principales mercados, otros productos como la "sangre de grado" que también fueron apropiados ilícitamente.

Teniendo en cuenta estas experiencias y en cumplimiento de lo señalado en la Organización Mundial de la Propiedad Intelectual, podemos considerar que estos conocimientos producto de la transmisión oral de generación en generación, hoy son tenidos en cuenta y pueden en cualquier momento surtir sus efectos jurídicos. Falta aún una mayor divulgación y precisión de las funciones de este organismo regulador para beneficiar a una mayor población nativa. Por tanto, podemos considerar, que el Estado, está cumpliendo con su función protectora. 


\section{2.-"Artículo 10. Utilización sostenible de los componentes de la diversidad biológica. Inciso d):}

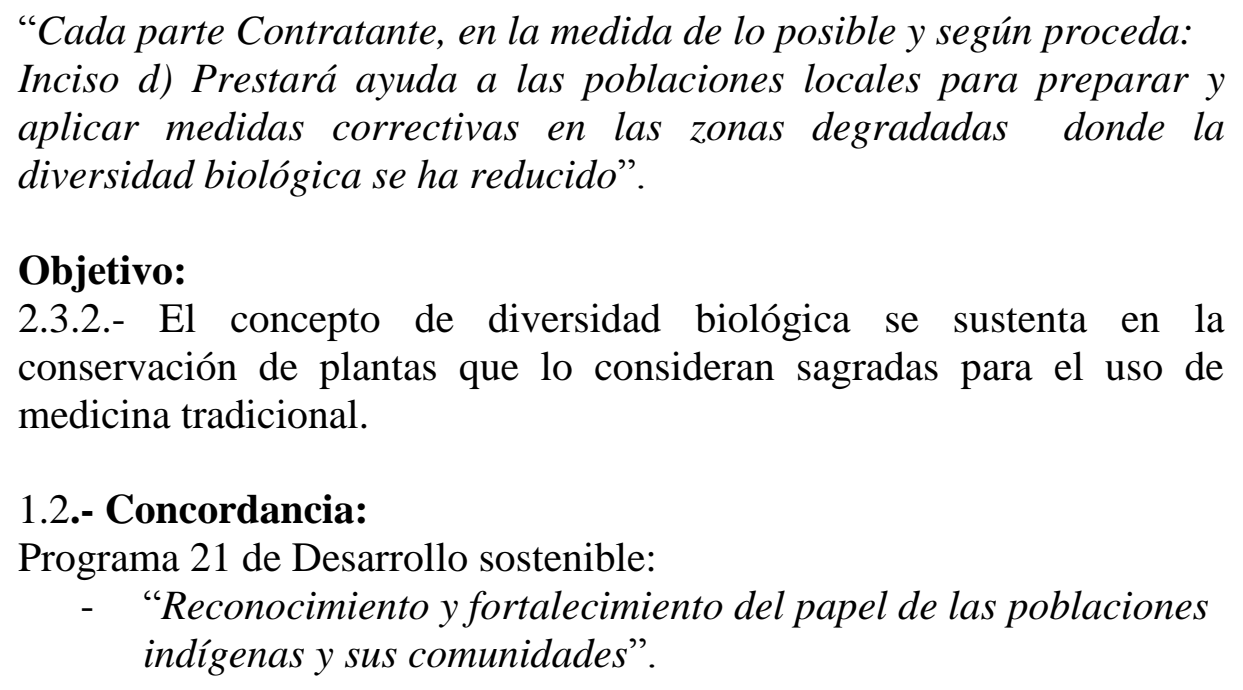

\subsection{1.- Comprobación del cumplimiento en función de la hipótesis}

El Estado como parte contratante del Convenio sobre la Diversidad Biológica, ha emitido un conjunto normativo. El Perú ha firmado y ratificado varios tratados internacionales, comprometiéndose a conservar el medio ambiente y el patrimonio natural y cultural. La Constitución Política del Perú (1993), Capítulo II, De los Tratados, Art. 55, establece que: "Los tratados celebrados por el Estado y en vigor forman parte del derecho nacional".

Estos son:

1. Tratados, convenciones, convenios y protocolos. Los principales tratados firmados y ratificados por el Perú, referentes al medio ambiente, los recursos naturales y la conservación del patrimonio natural y cultural son los siguientes:

2. Convención para la Protección de la Flora, de la Fauna y de las Bellezas Escénicas Naturales de los Países de América (Washington, 1940). Ratificada por el Perú en 1946. Es un compromiso para proteger áreas naturales y especies de flora y fauna.

3. Convención para el Comercio Internacional de Especies Amenazadas de Extinción (CITES). Firmada en 1973 y ratificada por el Perú en 1974. Compromete a establecer controles de comercio de productos y especies de flora y fauna amenazadas de extinción.

4. Acuerdo entre Perú y Brasil para la conservación de la flora y de la fauna de la Amazonía. Firmado en 1975 y que compromete a los dos países a cooperar en la conservación de la flora y fauna amazónicas.

5. Tratado de Cooperación Amazónica. Firmado en 1978 entre 8 países (Bolivia, Brasil, Colombia, Ecuador, Guyana, Perú, Surinam y Venezuela) para cooperar en un desarrollo armónico de la Amazonía. 
6. Acuerdo entre Perú y Colombia para la conservación de la flora y de la fauna de la Amazonía. Firmado en 1979. Establece un compromiso entre ambos países para cooperar en la conservación de la flora y fauna silvestres.

7. Convenio para la Conservación y Manejo de la Vicuña. Firmado entre Perú, Bolivia, Chile y Ecuador en 1979, y adherido por Argentina. Establece las normas y la cooperación entre los cinco países para la conservación y el aprovechamiento de la vicuña y el comercio de sus productos.

8. Convención para la protección del patrimonio mundial cultural y natural. Establecida por la UNESCO en 1972 y ratificada por el Perú en 1981. Establece un compromiso mundial para proteger el patrimonio cultural y natural del mundo y de los países.

9. Convenio sobre Diversidad Biológica. Firmado en Río de Janeiro en 1992 y ratificado en 1993, establece los compromisos mundiales y nacionales referentes a la identificación y monitoreo de la biodiversidad; la conservación in situ (áreas protegidas, introducción de especies foráneas, mantención y protección los conocimientos de las poblaciones locales) y ex situ (colecciones biológicas y bancos genéticos); el uso sostenible de los componentes de la biodiversidad; la investigación, capacitación, educación y conciencia públicas; el control y minimización de impactos negativos; el acceso a los recursos genéticos y a la tecnología; el intercambio de información y cooperación entre los países desarrollados y en desarrollo para la conservación y uso sostenible de la biodiversidad.

4.2.2.- CONCORDANCIA: Programa 21 Desarrollo sostenible. "Reconocimiento y fortalecimiento del papel de las poblaciones indígenas y sus comunidades”.

Si bien es cierto que la legislación existe, su implementación en muchos casos dejan mucho que desear. El propio Estado se convierte en un animador del incumplimiento, así sucede con un conjunto de Decretos Legislativos emitidos en ocasión de aprobar el tratado de libre comercio con los Estados Unidos produciéndose enfrentamientos entre la población nativa y la policía nacional, hecho conocido como "el baguazo".

El gobierno emitió el Decreto Legislativo No 1015 "que unifica los procedimientos de las comunidades campesinas y nativas de la sierra y de la selva con las de la costa para mejorar su producción y competitividad agropecuaria", con el que se pretende vender las tierras de las comunidades al mejor postor, bastando que una minoría de comuneros, bajo la forma de "no menos del 50\% de los asistentes a la asamblea", puedan decidir sobre la propiedad de su comunidad. La norma deroga el artículo 11 de la Ley 26505, que establece el requisito del voto favorable de no menos de los dos tercios de todos los miembros de la comunidad, para disponer de las tierras comunales en sierra y selva. Ahora, basta que un grupo mínimo de comuneros decidan venderlas para que las comunidades pierdan sus tierras, facilitando a que tan solo un treinta o cuarenta por ciento de los comuneros decidan la venta de las tierras de la comunidad o "ayllu" a una corporación minera, o a una empresa petrolera o urbanizadora según sean los casos.

La norma en mención vulnera la Constitución política en sus artículos $88^{\circ}$ y $89^{\circ}$ que establece que el Estado garantiza el derecho de propiedad sobre la tierra, en forma privada o comunal o en cualquier otra forma asociativa. El $89^{\circ}$ dice a la letra: "Las comunidades Campesinas y las Nativas tienen existencia legal y son personas jurídicas. Son autónomas en 
su organización, en el trabajo y en el uso y la libre disposición de su tierras, así como en lo económico y administrativo, dentro del marco que la ley establece. La propiedad de sus tierras es imprescriptible, salvo en el caso de abandono previsto en el artículo anterior. El estado respeta la identidad cultural de las Comunidades Campesinas y Nativas".

Lo que se pone en tela de juicio es la imprescriptibilidad de su territorio, la vulneración, por tanto es flagrante. Estos desencuentros de los gobiernosde la década de los ochenta y noventa han sido frecuentes, tanto por su autoritarismo como por la poca atención o descuido a dichas poblaciones.

En términos generales, los acuerdos adoptados y los pactos y tratados internaciones adoptados por el Perú son buenos y para su cabal cumplimiento, dejemos a los sucesivos gobiernos a fin de que sea una realidad efectiva.

\subsection{3.- El convenio 169 OIT}

En el marco de los derechos humanos, la Organización Internacional del Trabajo aprobó dicho convenio con la finalidad de que los pueblos indígenas y tribales deberán gozar plenamente de los derechos humanos y libertades fundamentales, sin obstáculos ni discriminación. Las disposiciones de este Convenio se aplicarán sin discriminación a los hombres y mujeres de esos pueblos. No deberá emplearse ninguna forma de fuerza o se coerción que viole los derechos humanos y las libertades fundamentales de los pueblos interesados, incluidos los derechos contenidos en el presente Convenio ${ }^{244,}$.

De conformidad con este dispositivo del cual el Estado peruano es parte y lo reconoce, y al aplicar las disposiciones del presente Convenio, los gobiernos deberán "a) consultar a los pueblos interesados, mediante procedimientos apropiados y en particular a través de sus instituciones representativas, cada vez que se prevean medidas legislativas o administrativas susceptibles de afectarles directamente) establecer los medios a través de los cuales los pueblos interesados puedan participar libremente, por lo menos en la misma medida que otros sectores de la población, y a todos los niveles en la adopción de decisiones en instituciones electivas y organismos administrativos y de otras índoles responsables de políticas y programas que les conciernan ${ }^{245}$.

Varias ONGS han cuestionado el controvertido DL 1015, sostienen que "es sumamente peligrosa" pues convulsiona la paz en el país al pretender individualizar a los campesinos y nativos y que los hacen presa fácil de la voracidad de quienes pretendan arrebatarles sus tierras, vulnerando sus derechos. Otros han dejado deslizar que las tierras solo serán vendidas por la fuerza. Los efectos no se dejaron esperar.

A los tres días de publicada este Decreto Legislativo, las organizaciones indígenas convocaron una conferencia de prensa en el local de la Confederación Nacional Agraria (CNA). La coalición indígena integrada por la Confederación Campesina del Perú (CCP), la Confederación Nacional Agraria (FNA), la Confederación Nacional de Comunidades del Perú Afectadas por la Minería (CONACAMI) y la Asociación Interétnica de Desarrollo de la Selva Peruana (AIDESEP), han dicho que se encuentran en estado de emergencia, por tanto,

\footnotetext{
${ }^{244}$ Artículo 3 del Convenio.

${ }^{245}$ Artículo 6 del convenio.
} 
han acordado realizar una serie de acciones de protesta desatándose así el conflicto social con nefastas consecuencias.

Los problemas no han sido solucionados pacíficamente y se mantienen latentes, el goce pleno de los derechos humanos y de las libertades fundamentales sin obstáculos ni discriminación, son tenidas en cuenta, pero carece de implementación. El convenio 169-OIT es muy claro, debe existir un organismo del Estado que implemente la "consulta previa" para todos los efectos del trato en cuanto a la utilización de los recursos naturales. A nivel del gobierno se están formulando proyectos de propuestas, sin llegar a su materialización.

Lo más importante en estos casos, es difundir los alcances del convenio citado, que desde mi punto de vista, marca un hito en la historia y en la vida de los pueblos originarios en todas sus formas. En lo que respecta a las formas de administrar justicia, son estos pueblos que lo hacen en forma correcta, respetando el debido proceso comunal, dando oportunidad a que, el juzgado, tenga el derecho de su defensa. Este constituye, la fuente del derecho. Por su puesto, la paz en las comunidades nativas es el reino de ellos, los problemas jurídicos, son pasajeros.

\subsection{4.-Directrices de Addis Abeba ${ }^{246}$}

El ejecutivo al no tener en cuenta el convenio 169 al momento de emitir la legislación sobre la disponibilidad de las tierras de las comunidades campesinas y nativas, tal como lo vimos anteriormente, tampoco lo tuvo con el principio doce de las directrices y principios de Addis Abeba, por cuanto con frecuencia, las comunidades indígenas y locales y los interesados locales directos, asumen costos importantes o se privan de los beneficios del uso potencial de la diversidad biológica a fin de garantizar o mejorar los beneficios que otros acumulan.

Muchos recursos (por ejemplo, la madera, la pesca) están excesivamente explotados porque las reglamentaciones se ignoran y no se hacen cumplir. Cuando la gente local participa como interesada directa disminuyen, en general, los regímenes de gestión se mejoran cuando se aplican programas constructivos que benefician a las comunidades locales, como instrucción para capacidades que pueden ofrecer alternativas de ingresos o asistencia en la diversificación de sus capacidades de gestión. Las recomendaciones de las directrices deben ser tenidas en cuenta en todo momento al tomar decisiones que afecten directa o indirectamente a dichas comunidades, por lo que el gobierno antes de tomar esta decisión, debería asesorarse por la secretaría ejecutiva de la oficina de Addis Abbeba.

\footnotetext{
${ }^{246}$ Los Principios y Directrices de Addis Abeba para la utilización sostenible de la diversidad biológica prestan asistencia a los gobiernos, a las comunidades indígenas y locales, a los administradores de los recursos, al sector privado y a otros interesados directos proporcionándoles la forma de asegurar que los usos que hagan de la diversidad biológica no llevarán a su declive a largo plazo. Los catorce principios por su mutua dependencia deberían ser considerados conjuntamente. Los principios son de pertinencia general. Su aplicación dependerá consiguientemente de la diversidad biológica que esté siendo considerada, de las condiciones reinantes, y del contexto institucional y cultural en el que tiene lugar su utilización.
} 


\section{5.- Analogías}

\section{1.- La Unión Europea: utilización sostenible de la biodiversidad. Artículo 10 del convenio incisos $a$ ), b), c) y d).}

Los incisos a), b),c) y d) del artículo 10 del Convenio, son tenidos muy en cuenta por los países de la Unión Europea (veinte y siete integrantes). Revisando la literatura correspondiente al Convenio de la Diversidad Biológica respecto a la Unión Europea, se llega a comprobar que ésta cubre un área geográfica muy vasta y diversa, que alberga numerosos tipos de ecosistemas y especies. Sin embargo, la diversidad biológica se encuentra amenazada a todo lo largo y ancho de la Unión Europea. Según la Agencia Europea de Medio Ambiente (AEMA) y otras organizaciones, el tamaño de los hábitats sigue disminuyendo y están cada vez más fragmentados en forma similar con lo que ocurre en las comunidades nativas dela Amazonía peruana.

Como resultado, los servicios de los ecosistemas se están deteriorando y muchas especies autóctonas se encuentran amenazadas. Por ejemplo ${ }^{247}$, Europa ya ha perdido aproximadamente la mitad de sus humedales, (previsto en el convenio Ramsar), así como amplias zonas de pastizales. Se calcula que cerca del cuarenta por ciento de los mamíferos europeos están en peligro, entre ellos el zorro ártico, ardillas autóctonas, delfines y focas, y algunos de ellos, como el lince ibérico están al borde de la extinción. Asimismo, casi el cuarenta por ciento de las aves y el cuarenta y cinco por ciento de las mariposas, junto con muchas especies de reptiles y anfibios de Europa, están en situación de riesgo. Gran número de plantas autóctonas se han vuelto raras o se encuentran amenazadas.

Tanto el Convenio de Diversidad Biológica como la estrategia europea de biodiversidad, reconocen que las personas, son parte de la naturaleza y que los recursos biológicos deben utilizarse de forma sostenible. No obstante, es urgente que se pongan en marcha políticas y medidas legislativas para garantizar una explotación de los recursos biológicos que no ponga en peligro su viabilidad a largo plazo ni la supervivencia de otras especies. En la UE ya se han producido importantes avances en la armonización de las prácticas agrícolas, pesqueras y forestales, en línea con el artículo 10 del convenio de diversidad biológica ${ }^{248}$.

Las prácticas agrícolas inapropiadas han provocado la reducción de la diversidad biológica tanto en las tierras de cultivo como en sus alrededores. Las poblaciones de ciertas especies de aves de estas áreas han disminuido en las últimas décadas. Por ello, el objetivo del Plan de acción sobre biodiversidad en la agricultura es reducir el impacto medioambiental de las actividades agropecuarias.

Muchos de los hábitats ricos en biodiversidad que necesitan medidas de conservación están situados en terrenos dedicados a la agricultura o en sus proximidades. Por ello, estos

\footnotetext{
${ }^{247}$ Convenio sobre la Diversidad Biológica. Aplicación en la Unión Europea. Hay que esforzarse más paracumplir los objetivos de 2010.

${ }^{248}$ Los acuerdos internacionales sobre medio ambiente, como el Convenio sobre la diversidad biológica (CDB), son ratificados por la Comunidad Europea (CE) — que es una organizaciónde integración económica regional con personalidad jurídica- y por sus Estados miembros. Conjuntamente, la CE y sus Estados miembros forman la entidad política denominada Unión Europea. La mayoría de las normas de la UE deben ser aprobadas por el Consejo de Ministros, que representa a los gobiernos de los 27 Estados miembros, y por el Parlamento Europeo, cuyos 785 miembros son elegidos directamente por los ciudadanos europeos.
} 
hábitats requieren, para su mantenimiento, una gestión apropiada. Con su Política de Desarrollo Rural, la UE quiere reducir los efectos negativos que la agricultura causa al medio ambiente y, a la vez, conciliar las necesidades del sector agrícola con los objetivos del convenio de diversidad biológica. Para alcanzar esta meta, se han puesto en marcha una serie de medidas agromedioambientales, cuyo fin es impulsar a los agricultores a proteger y mejorar el entorno y la biodiversidad mediante métodos que van más allá de las buenas prácticas agropecuarias tradicionales.

Las actividades humanas han aumentado las amenazas sobre los ecosistemas marinos y costeros, y sobre las aguas continentales. La preocupación por la biodiversidad debe, por tanto, estar presente en la gestión de los recursos marinos, el agua y la pesca. Así pues, con la Estrategia europea para la biodiversidad se presentaron unos ambiciosos objetivos para el sector pesquero y, a su vez, mediante el Plan de acción sobre biodiversidad en la pesca, adoptado en 2001, se hicieron varias recomendaciones específicas para proteger la biodiversidad frente al impacto de la pesca marina y la acuicultura. Adoptado en 2002, el Plan de acción para integrar la protección medioambiental, contiene unos principios guía.

Unas medidas de gestión y un programa de trabajo destinado a introducir gradualmente un enfoque ecológico en el sector pesquero y a limitar el impacto medio ambiental de la Política Pesquera Común. Los bosques cubren aproximadamente un tercio de las tierras del planeta y albergan la inmensa mayoría de la biodiversidad terrestre. Por ello, la deforestación y la degradación de las zonas forestales reducen gravemente la diversidad biológica. Se necesita, evidentemente, una acción internacional y regional que coordine a su vez todas las actividades nacionales para promover la gestión sostenible de los bosques y la conservación de la biodiversidad. La UE, aparte de impulsar la puesta en práctica del programa de trabajo ampliado del CDB sobre biodiversidad forestal, apoya también otras iniciativas internacionales para la conservación de la diversidad biológica. Sirve como ejemplo su participación en el Foro de las Naciones Unidas sobre los Bosques; además, la Unión Europea es miembro del Convenio internacional de las maderas tropicales.

La Unión Europea toma en serio el convenio, los organismos encargados de velar por su cumplimiento, parten del seno mismo de dicha unión, es la asamblea general la que toma en última instancia la palabra final; a ello hay que agregar, que las poblaciones nativas son poco numerosas comparadas en las naciones sudamericanas por ejemplo y ni hablar de las comunidades nativas de la Amazonía peruana.

Crean sus propias instancias, la depredación de las especies marinas por ejemplo, a la que hacen referencia sus informes, son propias de las actividades pesqueras de empresas balleneras por ejemplo. En nuestra selva no existen estas especies, solo peces de diversos tamaños, que son depredados por pescadores artesanales y otros provenientes de países vecinos. Son realidades distintas, pero el problema es uno solo.

\section{A manera de conclusión.}

El cumplimiento de los incisos c) y d) del artículo 10 del Convenio sobre la Diversidad Biológica en las Comunidades Nativas de la Amazonía peruana, se está cumpliendo gracias a la energía puesta por los miembros de dichas comunidades. Se observa un permanente deterioro de los bienes como las tierras, los bosques, así como la apropiación de su conocimiento tradicional, a pesar de que el gobierno ha emitido un conjunto de normas a fin de evitar su depredación. 
Se observa que existe hoy una contradicción entre las normas emitidas por el gobierno a fin de proteger toda la biodiversidad en estas áreas con los Decretos Legislativos para acelerar el Tratado de Libre Comercio con los Estados Unidos que exige el cumplimiento de las normas internacionales, sin embargo, son ellos los que no han firmado los convenios y tratados como el de los Derechos Humanos del que los EU no forma parte. Esta es otra contradicción flagrante. Estos hechos, dan lugar a conflictos entre las poblaciones delas Comunidades Nativas con el gobierno.

La situación de depredación de la biodiversidad es similar en la Unión Europea, con la diferencia que ellos han elaborado planes de contingencia a fin evitar su aniquilamiento. Sus normas obligan a todos sus miembros por igual para que su cumplimiento se dé en los plazos fijados de antemano.

\section{BIBLIOGRAFÍA}

Aldecoa, F. (2002) La Integración Europea: Análisis Histórico Intercultural. Madrid: Tecnos.

BARCLAY, F., BURGA, E., SMITH, R., CHICCHON, A., CHIRIF, A., HUERTAS., B., IVICHE, A. y, SHEPARD, G.(2003). Los pueblos amazónicos y las reservas indígenas: Santuarios Nacionales del Perú. Tomo 7. Lima: PEISA SAC.

BIODAMAZ,(2004). Sistema de Información de la Diversidad Biológica y Ambiental dela Amazonía Peruana Iquitos Perú. 77 p.

BIODAMAZ, (2004). Macrounidades Ambientales en la Amazonía Peruana con Énfasis en la Selva Baja: Primera Aproximación a manera de hipótesis de trabajo. Iquitos: Documento técnico No 13IIAP.

BIODAMAZ. (2001). Estrategia Regional de la Diversidad Biológica Amazónica. Documento Técnico Iquitos: IIAP.

BLANCO, L. (1986). Diagnóstico de la Actividad Forestal del Departamento de Ucayali. Lima.

BRAKO, L.. y, ZARUCHI, J. (1993). Catálogo de Angiospermas y Gimnospermas del Perú. . Missouri: Botanical Garden.

CAMARA NACIONAL FORESTAL. (2004). El potencial maderero de Ucayali y la tala ilegal. Pucallpa: Foros Regionales.

CONAM.( 2001). Informe Nacional sobre Diversidad Biológica. Lima, Primera edición.

CONAM.( 2001). Informe Nacional del Estado del Ambiente. Lima: Publicación digital.

CONAM.(1999). Estrategia Regional para la Conservación y Utilización Sostenible de la Diversidad Biológica Lima. Punto Focal Regional de Ucayali.

CONAM. (1998). Plan Estratégico para la Conservación y Utilización Sostenible dela Diversidad Biológica de la Región Ucayali. Pucallpa: Informe.

CONAM y GOREU. (2004). Política y Plan de Acción Ambiental. Lima: Primera edición.

FDA y CRP. (2001). Evaluación y Diagnóstico de Áreas Reforestadas por el Comité de Reforestación de Pucallpa Periodo 1983 - 2000. Pucallpa.

Gobierno Regional de Ucayali.(2005). Propuesta para la creación de áreas de conservación regional Isconahua y Murunahua-Tamaya: consideraciones generales. Ucayali: Gerencia Regional de Recursos Naturales y Gestión del Medio Ambiente

IFEA. (1994). Las Palmeras del Perú. Colección patrones de distribución geográfica, ecología, estatutos de conservación, nombres vernáculos, utilizaciones. Lima.

INADE. (2001). Plan De desarrollo sostenible de la amazonia: Ucayali. Delimitación dela unidad geoeconómica del área de estudio II Ucayali. Lima. 
INEI. (2005). Guía Estadística Departamental Conociendo Ucayali 2003-2005. Pucallpa: disco compacto $8 \mathrm{~mm}$.

IIAP, CONAM. (1999). Diversidad biológica estrategia Perú. Ucayali: Estrategia Regional para la Conservación y utilización sostenible de la Diversidad Biológica. Lima: IIAP

INRENA. (2005).Participación de las comunidades nativas en la co-administración de la Reserva Comunal El Sira. Lima: Intendencia Nacional de Áreas Naturales Protegidas.

INRENA. (2005). Estadística de flora y fauna. Pucallpa.

INRENA. (2004). Sistema Ambiental Estratégico para el Bajo Urubamba - Informe final. Lima: Oficina del Grupo Técnico de Coordinación Inter-Institucional

INRENA.(2002). Diagnóstico Forestal y de Fauna Silvestre. Administración Técnica Forestal de Pucallpa. Pucallpa.

INRENA. (1997). Estudio Nacional de la Diversidad Biológica. Lima: Diagnóstico Nacional. Mayor, P., y Bodmer, R.. (2009).Pueblos Indígenas de la Amazonía Peruana Lima: Centro de Estudios Teológicos de la Amazonía (CETA).

NALVARTE, W. (1999). Plantas Amazónicas de uso medicinal. Diagnóstico de un sector económico con un potencial de realización. Lima: Universidad Nacional Agraria la Molina.

PERU. (2004). Categorizar a la Zona Reservada del Alto Purús como Parque Nacional Alto Purús y Reserva Comunal Purús. D.S Nº40-2004- AG. Lima: El Peruano.

PROYECTO ESPECIAL DE TITULACIÓN DE TIERRAS (PETT). (2000). Lima: Directorio de Comunidades Nativas del Perú.

QUEVEDO, M. (2003). Interpretación y análisis de la información de la encuesta al sector forestal industrial de Ucayali. Pucallpa.

TELLO, F., QUEVEDO, A. y GASCHE, J. (2004). Sistema de incentivos para el manejo de bosques de Loreto: El caso de los recursos forestales maderables. Iquitos IIAP -CIES.

VIVANCO, L. (2002). Gran Enciclopedia de la Región Ucayali: Identidad Regional. Séptima edición Lima: Vivanco Pimentel E.I.R.Ltda.

Internet:

www.inei.gob.pe

www.pronaturaleza.org/sierradeldivisor.htm

www.fieldmuseum.org/cordilleraazul.htm

www.aduanas.gob.pe

www..europa.eu.int/comm/enviroment/life 